\title{
Droplet Microarrays: From Surface Patterning to High-Throughput Applications
}

\author{
Wenqian Feng, Erica Ueda, and Pavel A. Levkin*
}

High-throughput screening of live cells and chemical reactions in isolated droplets is an important and growing method in areas ranging from studies of gene functions and the search for new drug candidates, to performing combinatorial chemical reactions. Compared with microfluidics and well plates, the facile fabrication, high density, and open structure endow droplet microarrays on planar surfaces with great potential in the development of next-generation miniaturized platforms for high-throughput applications. Surfaces with special wettability have served as substrates to generate and/or address droplets microarrays. Here, the formation of droplet microarrays with designed geometry on chemically prepatterned surfaces is briefly described and some of the newer and emerging applications of these microarrays that are currently being explored are highlighted. Next, some of the available technologies used to add (bio-)chemical libraries to each droplet in parallel are introduced. Current challenges and future prospects that would benefit from using such droplet microarrays are also discussed.

\section{Introduction}

During the last 30 years, the concept of miniaturization has been actively applied to the fields of biological and chemical analysis. ${ }^{[1-3]}$ Droplets are suited to compartmentalize and isolate reactants, and with the ability to mimic diverse conditions similar to that of a macroscale reactor, hence the use of microdroplets to perform miniaturized (bio-)chemical experiments is appealing. The combination of high droplet throughput, well-defined droplet size for ultrasmall-volume synthesis and analysis $^{[4]}$ as well as the compatibility of droplet arrays with indexing of individual droplets renders droplet-based technology an ideal platform for miniaturized high-throughput applications.

Liquid-liquid segmented microfluidics is a well-established droplet-based platform offering a great number of

Dr. W. Feng, Dr. E. Ueda, Dr. P. A. Levkin

Institute of Toxicology and Genetics

Karlsruhe Institute of Technology

Hermann-von-Helmholtz Platz 1

76344, Eggenstein-Leopoldshafen, Germany

E-mail: levkin@kit.edu

Dr. P. A. Levkin

Institute of Organic Chemistry

Karlsruhe Institute of Technology

76131 Karlsruhe, Germany opportunities in chemical and biological research. ${ }^{[1,5-7]}$ It uses monodisperse droplets with the volume down to femtoliters immersed in a second immiscible continuous phase within closed microfluidic channels (Figure 1A), thus enabling work with extremely small reagent amounts in physically isolated droplets. To prevent droplets from rapidly coalescing inside the devices, proper surfactants are often added to the continuous phase to stabilize the fluid-fluid interfaces of the droplets. ${ }^{[8]}$ Even with surfactants, however, droplets are not completely sealed as small molecules can diffuse through the surfactant layer into the continuous phase, leading to a risk of cross-contamination. ${ }^{[9]}$ The crosstalk between surfactants and the (bio-)chemical reaction components within the droplets and the difficulty to index experiments in individual droplets still need to be solved.

Unlike microfluidics where experiments are compartmentalized in series (Figure 1A), reactions can also be compartmentalized in an array format using well plates (Figure 1B). An important advantage of the array format is the defined location of each microreservoir, enabling simple indexing of each well and easy time-lapse measurements. The physical walls in microtiter plates prevent chemical and optical crosstalk between the neighboring wells. For instance, the vast majority of cell-based high-throughput screening (HTS) is performed in commercial 96-, 384-, and 1536-well microtiter plates. ${ }^{[10-12]}$ When dealing with very large numbers of samples on microtiter plates, pipetting sample solutions into the open wells in parallel cannot be done without matching liquid handling robotics that are generally designed for large industrial companies and suffer from several issues such as high costs and complexity of the instrumental setup. As the complexity of the microtiter plates and the number of features increase, further miniaturization of this platform becomes more and more important. Consequently, Whitesides and co-workers fabricated large arrays of microwells with diameter down to $2 \mu \mathrm{m}$ on poly(dimethylsiloxane) (PDMS), ${ }^{[13]}$ which allowed them to create ordered 2D arrays of microcrystals encapsulated in the microwells. ${ }^{[14]}$ Picowell plates consisting of millions of small wells (less than $50 \mu \mathrm{m}$ in diameter) were also applied for genome sequencing. ${ }^{[15]}$ Embedding the droplets into these microwells, however, adds further complication to experimental manipulations, such as adding chemical libraries. By combining the features of microfluidic platforms and microwells, Ismagilov and co-workers developed 
a SlipChip that enables precise and parallel addition of nanoliter volumes of solutions into microwells by sliding a top plate containing corresponding wells preloaded with samples of interest. ${ }^{[16,17]}$

Generation of 2D droplet microarrays (DMAs) on prepatterned planar surfaces (Figure 1C) could be considered as a combination of the microtiter plate and microarray technology. ${ }^{[18,19]}$ Instead of the surrounding oil phase in microfluidics or the physical wall in a microtiter plate, the chemically patterned regions behave as liquid repellent boundaries (for example, using superhydrophobic barriers) that prevent liquid movement and merging. As a consequence, droplets with complex geometries and with the size down to several micrometers or even nanometers ${ }^{[20]}$ can be generated on the planar surface without the need for surfactants. In addition, droplets can be positioned extremely close to each other on the surface without merging, ${ }^{[21]}$ which is essential for increasing the density of arrays and hence for the miniaturization and point-of-care applications. Accompanying the system miniaturization, several unique features arise from the 2D droplet microarray, as exemplified in Figure 1D: "openness" of the droplet microarrays makes droplets easily accessible and addressable from above the substrate and can substantially facilitate the multistep droplet manipulations required in many experiments such as chemical synthesis and cellular or biochemical assays; droplets can be analyzed directly on-chip using various techniques, for example, optical microscopy, electron microscopy, ${ }^{[22]}$ IR/Raman measurements, ${ }^{[23]} \mathrm{UV}$-vis, ${ }^{[24]}$ electrochemical assays, ${ }^{[25]}$ desorption electrospray ionization mass spectrometry (MS), ${ }^{[26]}$ matrixassisted laser desorption/ionization MS, ${ }^{[27]}$ etc.; and the accessibility of the microdroplets on the chips enables easy collection of samples from individual droplets and the consequent analysis such as $\mathrm{MS}^{[28]}$ and high-performance liquid chromatography. ${ }^{[29]}$

In this progress report, we discuss the preparation and some of the emerging applications of 2D droplet microarrays published over the last few years. In light of the substance dissolved or suspended in the droplet solution, the 2D microdroplets provide wide applications among cell-based high-throughput screening, controlled particle deposition, (bio)sensor fabrication, and chemical synthesis in droplets. For multistep experiments, droplet microarrays could become extremely useful as microreactors as soon as technologies for introducing reagents into each droplet mature. As a separate part, we give a brief introduction of the available technologies used to add (bio-)chemical libraries to each droplet in parallel. Finally, we will give an outlook on the foreseeable limitations, solutions, and other applications, which can benefit from using arrays of pico to microliter droplets.

\section{Applications of 2D Droplet Arrays}

\subsection{Cells in the Microdroplets}

\subsubsection{D Cell-Based High-Throughput Screening}

Cell-based assays represent approximately half of all highthroughput screens currently performed. ${ }^{[30]}$ Cell-based high-throughput screening has become an immensely important and widely used method in academia and industry in a variety of areas such as drug discovery. To increase the
Wenqian Feng obtained a

B.S. and M.S. in Chemical Engineering from Tianjin University, China in 2009 and 2012, respectively. He then joined Dr. Pavel Levkin's group at Karlsruhe Institute of Technology (KIT) as a Ph.D. student, graduating in Organic Chemistry from Heidelberg University, Germany in 2016. He worked on spatial surface functionalization via photoinduced reactions and using chemically patterned substrates to develop high-throughput screening platforms. Currently, he is a postdoctoral fellow at Lawrence Berkeley National Laboratory.

Erica Ueda obtained a B.S. from the University of California, Los Angeles in 2006 and an M.S. from the Massachusetts Institute of Technology in 2008 in Mechanical Engineering. She obtained her Ph.D. in the Faculty of Chemistry and Biosciences at Karlsruhe Institute of Technology in 2014. She conducted her Ph.D. research in the group of Dr. Pavel Levkin, focusing on using superhydrophilic-superhydrophobic patterned substrates to develop cell screening platforms such as cell, droplet, and hydrogel microarrays. She is currently the Chief Scientific Officer at Lifespans Limited, a medical device startup based in Hong Kong that is focused on orthopedic implants for the elderly.

Pavel Levkin is head of the Biofunctional Materials research group at Karlsruhe Institute of Technology (KIT), Germany. He graduated from the Institute of Fine Chemical Technology, Moscow and obtained Ph.D. in Organic Chemistry from the University of Tübingen followed by postdoctoral work at the University of California,

Berkeley. His research focuses on the development of functional and responsive materials, and surfaces for biomedical and biotechnological applications.

throughput of cell screening beyond the use of microtiter plates, cell microarrays have been developed. Thus, selective 
A

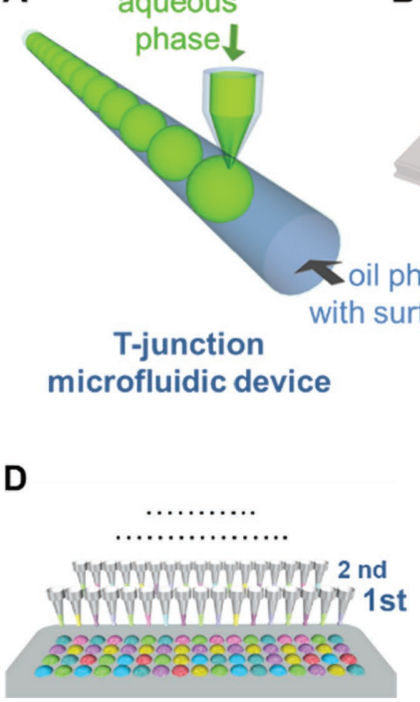

B

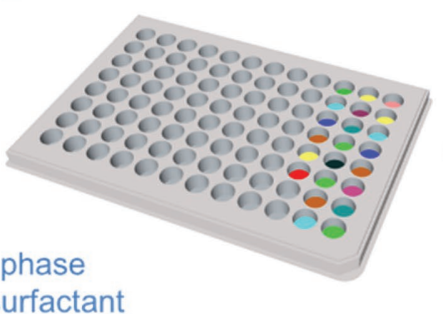

microtiter plate
C

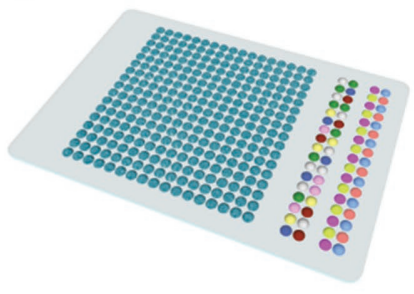

2D droplet microarray on a patterned substrate

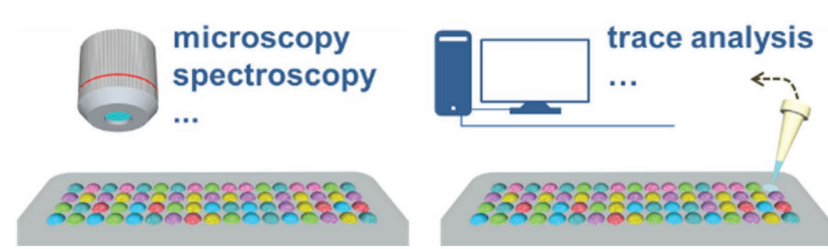

Figure 1. Schematic of high-throughput screenings in droplets A) in a microfluidic channel, B) in a well plate, and C) on a patterned planar substrate. D) Advantages arise from the open system of the droplet microarray. Left: multistep droplet manipulations; middle: analysis on-chip; right: sample collection and consequent trace analysis using external techniques.

modification of flat surfaces with antifouling polyethylene glycol (PEG) brushes, ${ }^{[31-34]}$ or the use of superhydrophobic barriers that also show cell-repellent properties, could be used to form high-density cell microarrays. ${ }^{[35-39]}$ With an increase in culture time, however, cells can proliferate both on the PEGylated surfaces and superhydrophobic surfaces, ${ }^{[40]}$ leading to crosscontamination between adjacent spots. In addition, since the patterned substrates are immersed and cultured in a connected culture medium, effective cell-cell communication between neighboring cell spots could take place (Figure 2A), ${ }^{[35]}$ which also limits the density of cell arrays and hence the throughput.

Droplet microarrays are an ideal alternative to address the limitations mentioned above. Each droplet can be regarded as an independent reservoir, and different cells and/or bioactive molecules can be trapped into these fully isolated compartments to perform biological reactions without crosscontamination (Figure 2B). Efremov et al. demonstrated the ability to control the spatial arrangement and geometry of multiple different cell types on a hydrophilic-superhydrophobic polymer micropattern for at least three days. ${ }^{[4]}$ Different cell suspensions were dispensed onto each hydrophilic area using a micropipette, thereby creating isolated culture microreservoirs confined to the geometry of hydrophilic regions surrounded by superhydrophobic barriers (Figure 2C,D). In that work, $50 \mu \mathrm{m}$ thin superhydrophobic barriers had proved effective in preventing merging of neighboring droplets and cell migration across the barriers despite the high initial cell density.

The method of pipetting each drop individually is not convenient, and a straightforward technique more suitable for high-throughput screening is strongly needed. By utilizing the phenomenon of discontinuous dewetting ${ }^{[13]}$ our group showed one-step formation of ultrahigh-density arrays of isolated pico- to microliter-sized aqueous droplets with defined geometry and volume (referred to as a DMA) on a superhydrophilic- superhydrophobic patterned surface, as schematically shown in Figure 2E. ${ }^{[21]}$ When rolling a bulk droplet across the superhydrophobic-superhydrophilic micropatterned substrate or pulling the whole substrate out of solution, the extreme wettability contrast between superhydrophilic and superhydrophobic patterns breaks the liquid film into thousands of microdroplets in each superhydrophilic spot (Figure 2F). An array of square superhydrophilic spots with side lengths of 1000,500 , and $350 \mu \mathrm{m}$ were used to trap droplets of 80,9 , and $3 \mathrm{~nL}$, respectively, which required about 600, 5000, and 15000 times less medium and reagents compared to 384-well microplates. ${ }^{\text {[22a] }}$

The volume of the produced droplets depends on various factors including surface tension of the solution, geometry of the hydrophilic spots, the way solution is applied, humidity, the presence of surface defects, the size of the "mother droplet," the size of the hydrophobic gap between the wettable spots, etc. However, by controlling these parameters, it is possible to keep the volume variability low, usually below $10 \%$. Thus, Chang et al. showed the formation of $11.5 \pm 0.5 \mathrm{~nL}$ water droplets on hydrophilic spots of $500 \mu \mathrm{m} \times 500 \mu \mathrm{m}$ on a superhydrophobic surface. ${ }^{[42 b]}$ The same authors also demonstrated that the volume can increase with larger gaps between hydrophilic spots. Figure 3 shows the ability to control droplet volumes from picoliters to hundreds of nanoliters and also demonstrates good variability of droplet volumes measured by counting the number of particles suspended in the droplets (Figure 3A), ${ }^{[134]}$ droplet heights (Figure 3B), ${ }^{[42 b]}$ or by measuring homogeneity of fluorescence intensity between droplets (Figure 3C,D). ${ }^{[21]}$

The small volumes of the droplets produced make DMA useful for single-step "printing" of precious reagents or even cells. Although hydrophobic barriers are also capable of splitting water into microdroplets through dewetting, using superhydrophobic barriers offers the advantage that makes very high-densities of microdroplets possible. ${ }^{[43]}$ For different 
A

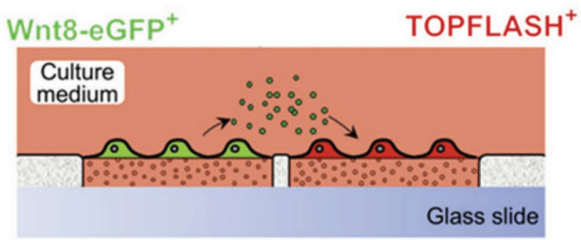

B

Highly Superhydrophobic

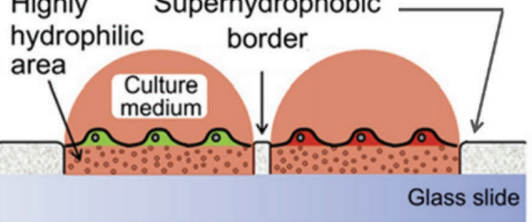

C $\quad 50 \mu \mathrm{m}$ superhydrophobic borders

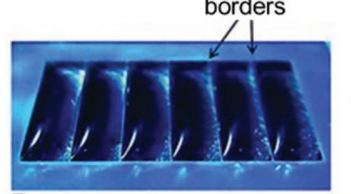
D

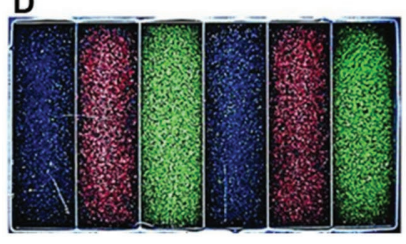

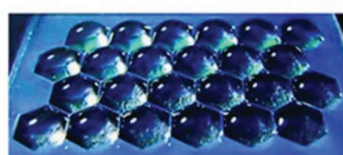

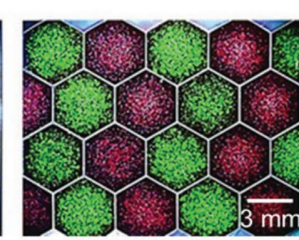

E

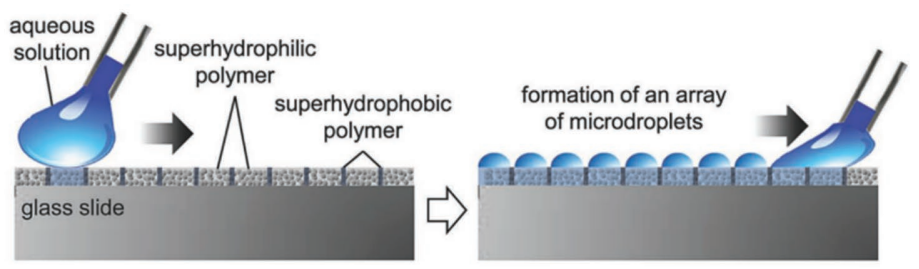

F
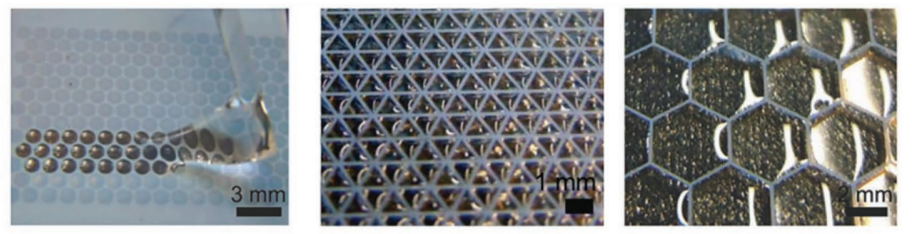

G
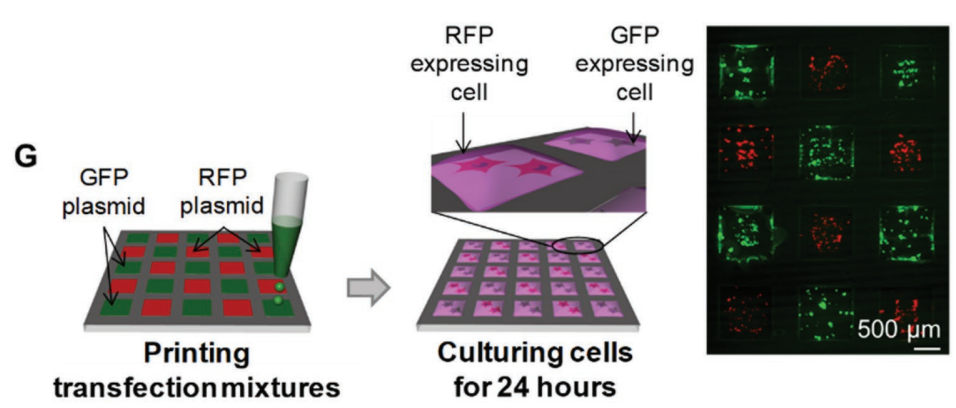

for 24 hours

Figure 2. Cell-based high-throughput screenings in 2D droplet microarrays. A) Schematic of the cell-cell communication between the neighboring cell populations in a connected culture medium. One cell population expresses the signaling molecules Wnt8, which influences the transcriptome of cells in the adjacent compartment. B) Schematic of cell culture in droplets on hydrophilic-superhydrophobic patterned polymer substrates. C) Hydrophilic-superhydrophobic patterns filled with water to form droplets of different geometries. D) Combined brightfield and fluorescence images of different cells patterned in different geometries and in close proximity. Reproduced with permission. ${ }^{[41]}$ Copyright 2012, Elsevier. E) Schematic of the single-step formation of a high-density array of separated microdroplets on a superhydrophilic-superhydrophobic patterned surface. During rolling of an aqueous solution along the patterned surface, the extreme wettability contrast of superhydrophilic spots on a superhydrophobic background leads to the spontaneous formation of completely separated microdroplets. F) Snapshot of water being rolled along a superhydrophilic-superhydrophobic patterned surface $(1 \mathrm{~mm}$ diameter circles, $100 \mu \mathrm{m}$ barriers) to form droplets only in the superhydrophilic spots. Droplets formed in triangular and hexagonal superhydrophilic patterns. Reproduced with permission. ${ }^{[2]}$ Copyright 2012, Royal Society of Chemistry. G) Reverse cell transfection in a 2D droplet microarray formed on a superhydrophilic-superhydrophobic patterned surface. Transfection mixtures containing plasmid DNA histone H2B-yellow fluorescent protein and histone H2B-red fluorescent protein are first printed onto superhydrophilic spots using a noncontact liquid dispenser and dried. HEK293 cells are seeded on the patterned surface to create a droplet microarray via discontinuous dewetting and then the preprinted chemicals start to dissolve in the individual microdroplets. Fluorescence microscope images are taken $24 \mathrm{~h}$ after seeding, showing the HEK293 cells transfected with H2BYFP (green) and H2B-RFP (red) in droplet microarrays. Scale bar, $500 \mu \mathrm{m}$. Reproduced with permission. ${ }^{[42 a]}$ Copyright 2016, Royal Society of Chemistry.

approaches to hydrophilic-superhydrophobic micropatterns and other applications, we refer to our recent review. ${ }^{[44]}$

Reverse cell transfection and drug screening using this Droplet Microarray were successfully demonstrated by printing transfection mixtures directly onto superhydrophilic spots on the substrate prior to one-step HEK293 cell seeding for cell screening (Figure 2G). ${ }^{[42 a]}$ In addition, high-throughput screening of mouse embryonic stem cells and cancer stem cells in droplet microarrays was also demonstrated. ${ }^{[45,46]}$ Tronser et al. demonstrated that porous superhydrophobic-hydrophilic micropatterns had the ability to inhibit differentiation of mouse embryonic stem cells (mESC) for up to $72 \mathrm{~h}$ in the formed droplets of nano-to-microliter size in array format, providing a mouse embryonic fibroblasts (MEFs)-free system for screening and investigation of mESCs in high-throughput manner. ${ }^{[4]}$ The difference in the behavior of mESCs was attributed to the special micro-nano topography of the polymer surface. ${ }^{[48]}$

\subsubsection{Single Cell Per Droplet}

High-throughput single cell analysis offers the possibility of analyzing individual cells in large scale and detecting the distribution of responses. ${ }^{[49-51]}$ Well-defined microdroplet generation could provide a simple but practical method for parallel immobilization of single cells at predefined positions on a surface. The open nature of the droplet microarrays allows for quick singlecell experiments and analysis such as (liquid- or gas-chromatography coupled) mass spectrometry ${ }^{[29]}$ in a high-throughput manner whilst being cost effective. As an example, Zhu et al. built up a droplet-based single-cell reverse transcription quantitative polymerase chain reaction ( $\mathrm{qPCR}$ ) system to quantify gene expression in individual cells. ${ }^{[52]}$ Droplets were printed on a hydrophobic-hydrophilic patterned silicon chip to form a droplet array (Figure 4A,B). To obtain the highest single cell occupancy in a droplet array, the cell suspension concentrations and the 
A
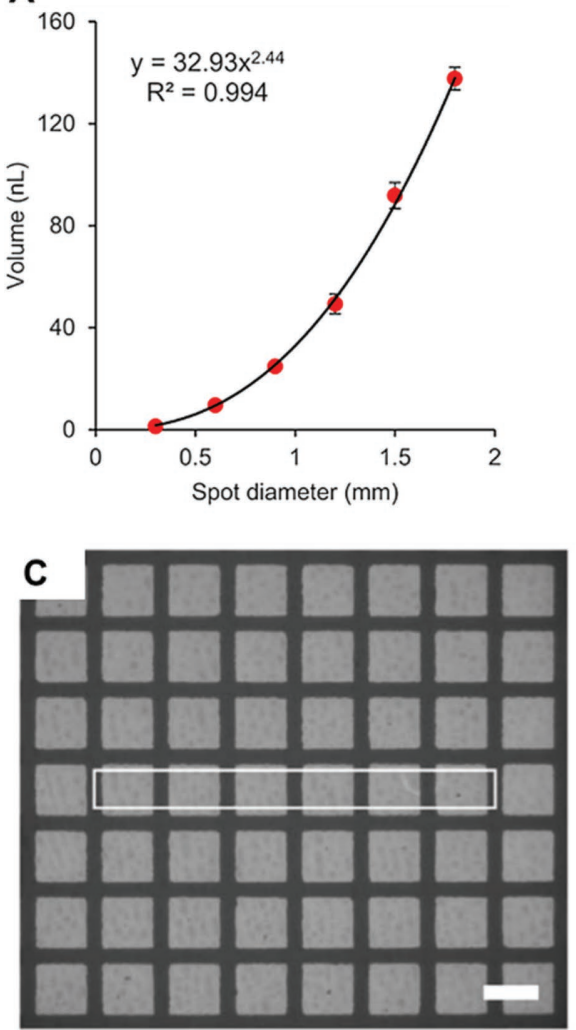

B
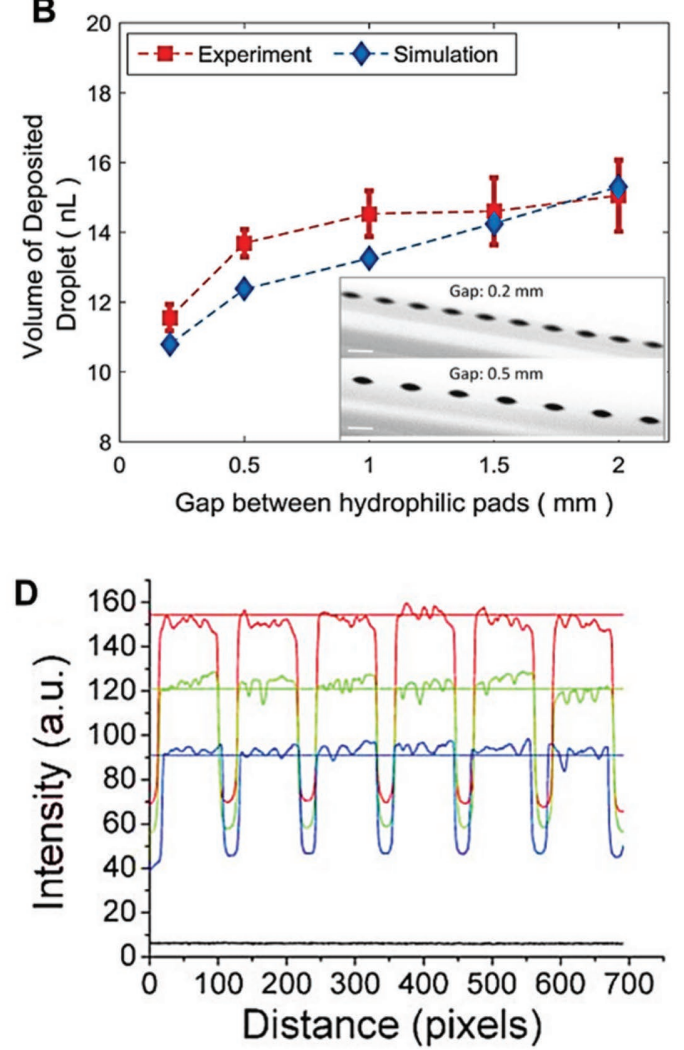

Figure 3. Quantification and reproducibility of droplet volumes formed on (super)hydrophobic-superhydrophilic patterned surfaces via discontinuous dewetting. A) The relationship between the volumes of the droplets and the sizes of the laser-cleaned hydrophilic spots ( $n>10$; the error bars denote the standard deviation of the mean volume). Reproduced with permission. ${ }^{[134]}$ Copyright 2016, American Chemical Society. B) The volume of deposited droplet as a function of gap between hydrophilic pads (square side length $0.5 \mathrm{~mm}$ ). The droplets are formed by sliding a droplet on a patterned hydrophilic/superhydrophobic surface tilted at $10^{\circ}$. Side view images of deposited droplets on pads with gaps of 0.2 and 0.5 mm are inserted. Scale bar is $500 \mu \mathrm{m}$. Reproduced with permission. ${ }^{[42 b]}$ Copyright 2016, American Institute of Physics. C) An example of a selected region to quantify droplet reproducibility. Grayscale fluorescence image shows $0.1 \mathrm{mg} \mathrm{mL}^{-1}$ Rhodamine $6 \mathrm{G}$ deposited on an array of superhydrophilic squares (500 $\mu \mathrm{m}$ side length, $62.5 \mu \mathrm{m}$ barrier) after drying in air. Scale bar is $500 \mu \mathrm{m}$. D) The fluorescence intensity profile of six squares from a representative sample for three different concentrations of Rhodamine 6G: $0.1 \mathrm{mg} \mathrm{mL}^{-1}$ (red), $0.05 \mathrm{mg} \mathrm{mL}^{-1}$ (green), $0.025 \mathrm{mg} \mathrm{mL}^{-1}$ (blue), and $0 \mathrm{mg} \mathrm{mL}^{-1}$ (black). The horizontal line is the mean fluorescent intensity across the triplicates, analyzed for each Rhodamine $6 \mathrm{G}$ concentration. Reproduced with permission. [21] Copyright 2012, Royal Society of Chemistry.

volume of produced microdroplets need to be optimized first. In this study, a highest probability of $35 \%$ for single cell encapsulation was achieved by printing droplets with $2 \mathrm{~nL}$ volume (cell concentration: $5 \times 10^{5}$ cells $\mathrm{mL}^{-1}$ ). To eliminate droplet evaporation, the silicon chip was covered with a layer of mineral oil.

Alternatively, Li et al. reported a facile strategy to create single live cell arrays by using the droplet-splitting method on a prepatterned substrate (Figure $4 \mathrm{C}$ ). ${ }^{[53]}$ When sliding a $10 \mu \mathrm{L}$ droplet of cell suspension on the superhydrophobic substrates with superhydrophilic patterns of $100 \mu \mathrm{m}$ lateral length, the superhydrophobic barriers split the droplet into uniform microdroplets, achieving parallel encapsulation of single human breast cancer cells (MCF7). Similarly, by using the method of limited dilution and varying cell density and seeding time, our group optimized the distribution of single cells $(20 \%$ single cells occupation) across the droplet microarray on our superhydrophobic-superhydrophilic patterned substrate. ${ }^{[5]}$ Culturing conditions for single cells in individual droplets on the droplet microarray were established as well, obtaining nearly $100 \%$ viability and a proliferation rate close to that of HeLa cells cultured by conventional methods.

\subsubsection{D Cell Culture}

Efforts to address the loss of tissue-specific properties in 2D monolayer cell cultures led to the development of 3D cell culture models in which cells would interact with neighboring cells and extracellular matrix components to form a complex communication network. Among the approaches for multicellular spheroids, one of the most well characterized models for $3 \mathrm{D}$ culture and screening, ${ }^{[55-57]}$ cell culture in arrays of hanging microdrops easily prevents cells from attaching to the culture ware substratum and thus allows for efficient formation of spheroids with defined sizes, cell numbers, and compositions. ${ }^{[58-60]}$

To further reduce the contact of cells to the culture ware, on microindentation patterned superhydrophobic polystyrene (PS) substrates, Mano and co-workers arranged arrays of hanging 

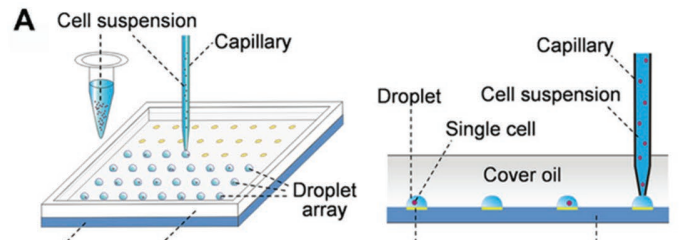

Silicoń chip Fráme

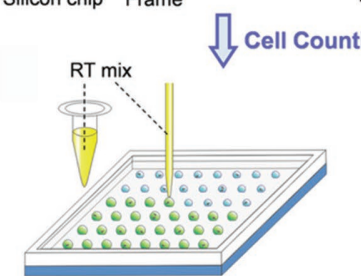

Hydrophilic spot Silicon chip

ting \& Heat Lysis

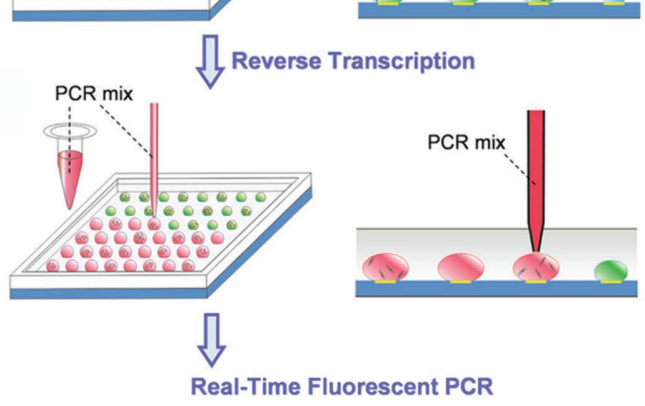

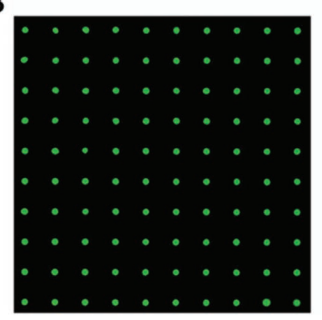

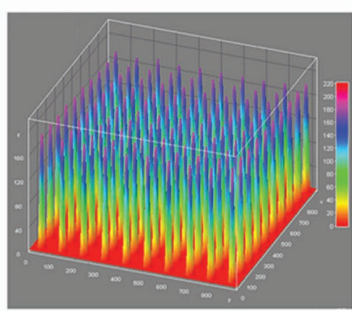

C

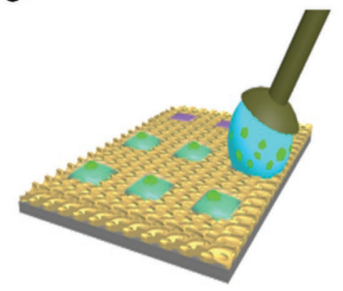

Rass etched silicon BSy superhydrophilic silicon

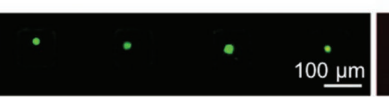

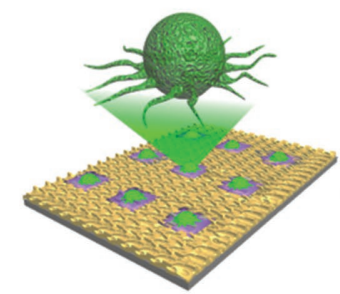

(2) superhydrophobic silicon cell

Figure 4. Culture of single cells in a 2D droplet microarray. A) Schematic diagrams showing the operating procedures of the droplet microarray for single cell gene expression analysis. Cell suspension is first printed on the hydrophilic spots of the silicon chip to generate a droplet array containing cells. After counting cell numbers in the droplets and thermally lysing the cells, reverse transcription mix is continuously added into each droplet to convert RNA to CDNA. PCR mix is then added into each droplet followed by real-time fluorescence PCR to quantify the gene expression levels. B) The fluorescence image and intensities of the $10 \times 10$ array of $2 \mathrm{~nL}$ droplets containing sodium fluorescein $\left(100 \times 10^{-3} \mathrm{M}\right)$, showing the high precision of the droplet manipulation. Reproduced under the terms of the Creative Commons Attribution 4.0 International License. ${ }^{[52]}$ Copyright 2015, Nature Publishing Group. C) Schematic of single cell isolation by splitting a droplet for femtoliter liquid arrays on a superhydrophilic-superhydrophobic patterned substrate. Bottom: Fluorescence images of a single human breast cancer cell (MCF7) array separated by splitting a droplet of cell culture medium (cell concentration: $10^{7} \mathrm{~mL}^{-1}$ ) on this micropatterned (100 $\mu \mathrm{m}$ lateral length) substrate. Cells had been stained by acridine orange/propidium iodide (AO/PI). The separated live cells emit green light under irradiation at $488 \mathrm{~nm}$ (left), and when exposed to light of $546 \mathrm{~nm}$ the cells are almost invisible (right), showing the successful isolation of single and live cells. Reproduced under the terms of the ACS AuthorChoice License. ${ }^{[53]}$ Copyright 2015, American Chemical Society.

cell culture droplets to build-up 3D spheroids. ${ }^{[61]}$ After placing droplets of cell suspensions over the microindentations, the substrates were inverted by $180^{\circ}$ such that the liquid droplets could hang in place (Figure 5A). The microgravity environment in each drop concentrated the cells and induced the formation of singular spheroids in each droplet at the liquid-air interface. Spheroids with different sizes and densities were obtained when cell suspensions with distinct cell numbers were used (Figure 5B). ${ }^{[62]}$ Specifically, because of the open nature of the droplet microarray system, the accessibility of droplets enabled culture medium exchange for long-term cell culture or drug addition for cytotoxicity testing. The quasi-spherical shape of the droplets allows low contact of the droplet to the substrate to be achieved and enhances the formation of spheroids although, at the expense of throughput since large indentation-to-indentation distances are necessary to prevent the neighboring droplets from merging. On a superhydrophobic PS surface patterned with smooth wettable spots, Oliveira et al. from the same group applied two different methods, dragging a drop of cell suspension over the patterned substrate or pulling the whole substrate out of the cell suspension, to generate an array of droplets. ${ }^{[63]}$ Compared with manual pipetting, the methods based on discontinuous dewetting exhibited a higher throughput and time-saving manner, especially suitable for surfaces patterned with a high-density of wettable spots.

\subsection{Hydrogel Micropads}

Hydrogels are hydrated crosslinked polymers resembling natural extracellular matrix, which provide soft, 3D support for cellular growth in a 3D microenvironment. In comparison to culturing cells in 2D monolayers, culturing cells in hydrogels better mimics the in vivo cell microenvironment making the functional cellular response more relevant. In addition, culturing cells in hydrogels allows for screening of nonadherent cells by immobilizing them in the hydrogel. By employing droplet microarrays, it is possible to generate miniaturized 3D hydrogel matrixes featuring individual complex cell microenvironments in a high-throughput manner. Thus, Salgado et al. used hydrophilic-superhydrophobic patterned substrates to perform a combinatorial screen of the chemical composition and cytocompatibility of 3D hydrogels in an array format. ${ }^{[64]}$ Twenty four polymer solutions containing chitosan, collagen, hyaluronic acid, gelatin, and alginate in different ratios were mixed with two different cell types, dispensed in the 


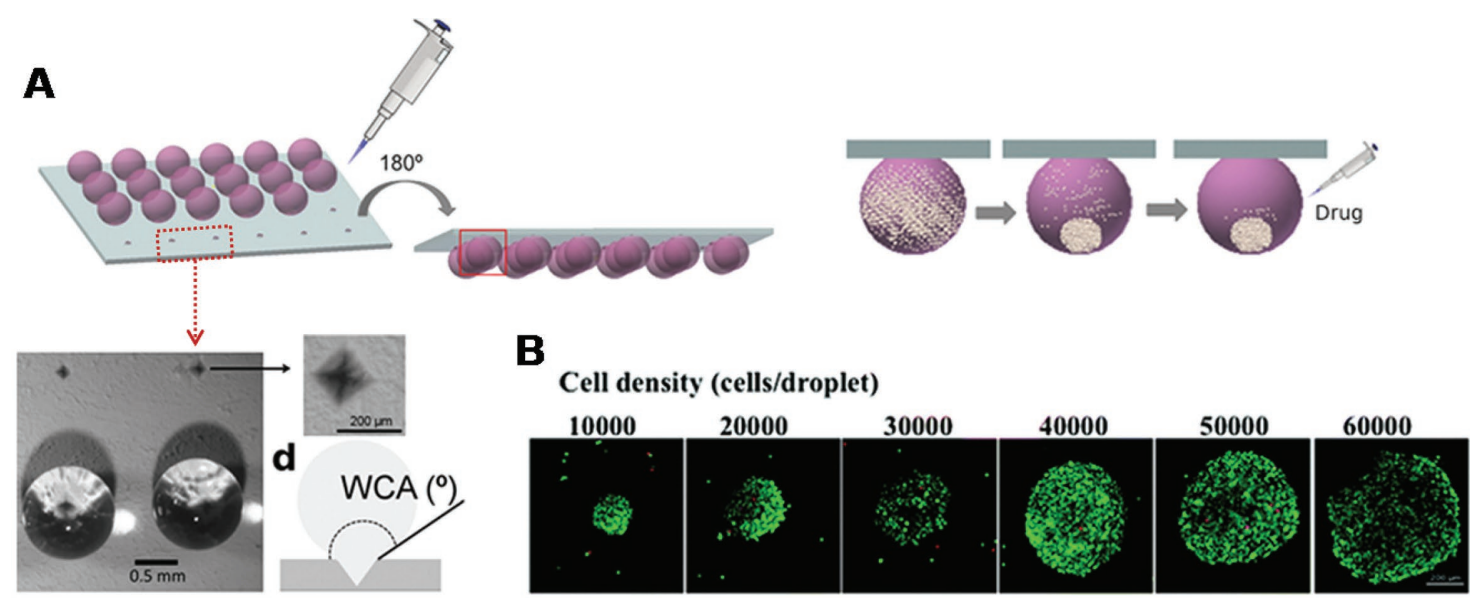

Figure 5. 3D cell culture in 2D droplet microarrays by using the hanging-drop method. A) Scheme of superhydrophobic surfaces patterned with microindentations able to suspend arrays of droplets containing cells, where water droplets are extremely repelled by the superhydrophobic substrate but penetrated into the indentations by capillary forces. By inverting the platform $180^{\circ}$, spheroids are formed at the liquid-air interface. Reproduced with permission. ${ }^{[61]}$ Copyright 2014, John Wiley and Sons. B) Fluorescence images of L929 spheroids with different sizes and densities after $48 \mathrm{~h}$ of culture. Scale bar, $200 \mu \mathrm{m}$. Reproduced with permission. ${ }^{[62]}$ Copyright 2015, Royal Society of Chemistry.

hydrophilic regions using a micropipette, and solidified by ionic crosslinking with $\mathrm{CaCl}_{2}$. Similarly, Li et al. applied hydrogel droplet microarrays with trapped antibody-functionalized beads for multiplexed protein analysis. ${ }^{[65]}$

Recently, an effective approach to heterogeneous 3D cell microenvironment arrays was introduced by Li et al. ${ }^{[66]}$ By spreading a hydrogel prepolymer on a hydrophilic-hydrophobic patterned surface, an array of microdroplets self-assembled in the hydrophilic spots via discontinuous dewetting and was transformed into a microgel array after gelation (Figure 6A). A microgel array containing human umbilical vein endothelial cells (HUVECs) was stacked with another top layer containing

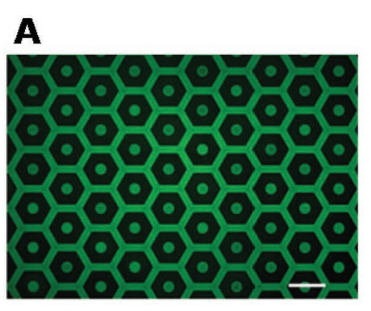

B
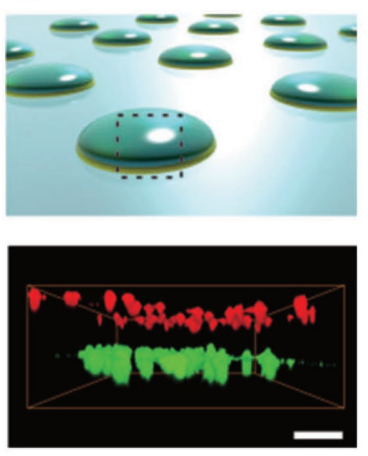

C

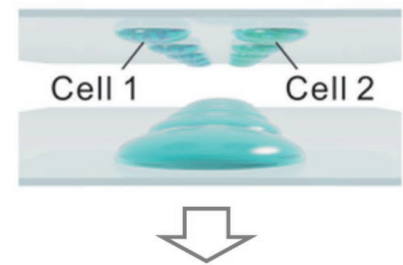

Cell 1
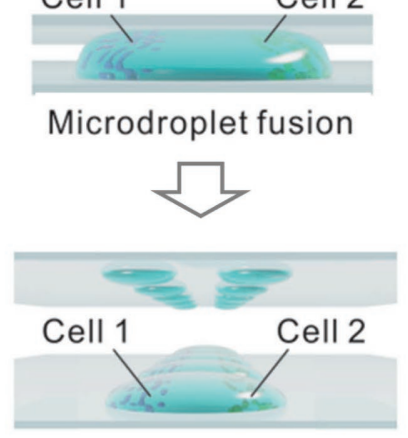

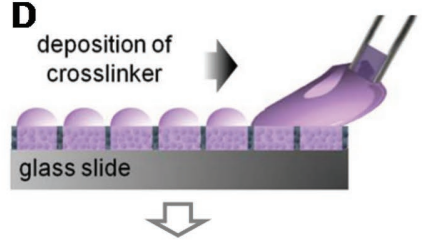

array filled with crosslinker

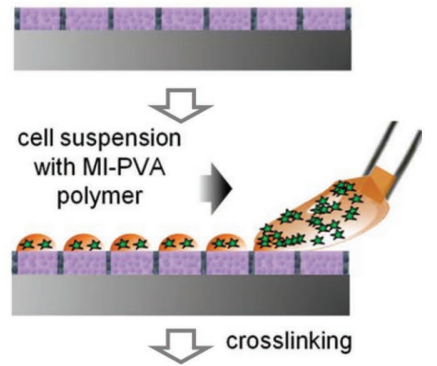

cells encapsulated in hydrogel micropads

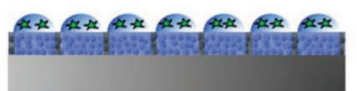

Figure 6. Formation of hydrogel microarrays via the droplet microarray strategy. A) Wettability-guided assembly of PEG microgels with complex architectures on a hydrophobic-hydrophilic prepatterned surface. B) Layer-by-layer assembly of two cell types in a single microgel. A microgel array containing HUVEC cells is stacked with another layer of fibroblast cells, confirmed by confocal fluorescence imaging. HUVEC cells are labeled with Dil (red) and fibroblasts are labeled with DiO (green). Scale bar, $50 \mu \mathrm{m}$. C) Schematics of side-by-side assembly of two cell populations in individual microgels for formation of the compartmentalized heterogeneous cell populations. Reproduced with permission. ${ }^{[66]}$ Copyright 2016, John Wiley and Sons. D) Schematic of the procedure used to produce arrays of hydrogel micropads incorporating cells on a superhydrophilic-superhydrophobic patterned porous layer. First, PEG-crosslinker is deposited in the superhydrophilic spots and then dried in air. Then, droplets of a cell suspension mixed with maleimide-functionalized polyvinyl alcohol are deposited using the rolling droplet method. Crosslinking occurs afterward to form separated hydrogel micropads encapsulating cells. Reproduced with permission. ${ }^{[21]}$ Copyright 2012, Royal Society of Chemistry. 
fibroblast cells, resulting in a layer-by-layer organization of heterogeneous cells in one microgel (Figure 6B). Formation of heterogeneous cell populations in a side-by-side spatial organization was also demonstrated by using a microdroplet fusion approach, where a pair of hanging microdroplets containing suspended HUVECs and fibroblasts were precisely fused into another large microdroplet (Figure 6C), showing the potential of using arrays of hydrogels with complex 3D microenvironments to study cell-cell or cell-matrix interactions in a miniaturized and high-throughput manner.

In our group, Ueda et al. demonstrated the applicability of the Droplet Microarray on superhydrophilic-superhydrophobic polymer micropatterns for creating high-density arrays of hydrogel micropads encapsulating live cells. ${ }^{[21]}$ PEG-crosslinker was first deposited in the superhydrophilic spots using discontinuous dewetting and then dried in air. Afterward, a new array of microdroplets containing maleimide-functionalized polyvinyl alcohol and cells was created using the same method, followed by crosslinking to form hydrogel micropads within minutes (Figure 6D). The formation of arrays of 3D hydrogel micropads can facilitate the screening of nonadherent cells by immobilizing the nonadherent cells within each microspot, avoiding the problem of washing the nonadherent cells away if subsequent steps such as medium exchange over the whole substrate or immersion of the substrate in a solution are needed. In another study, our group used superhydrophobichydrophilic micropatterns for the high-throughput fabrication of freestanding alginate hydrogel particles with defined geometries for 3D cell culture and cell screenings. ${ }^{[67]}$ The ability to create arrays of hydrogel micropads encapsulating live cells in a simple and inexpensive way is important for enabling high-throughput screening of cells in physiologically relevant environments. It is important to emphasize that the hydrogel size depends on the size of hydrophilic spots and hydrogel micropads can be detached to form free standing cell-laden hydrogel particles. This makes this system highly flexible and more versatile than the use of plastic microtiter plates.

\subsection{Polymer Deposition}

Usually patterned (super)hydrophobic-(super)hydrophilic surfaces exhibit dewettability contrast only with high surfacetension liquids such as water or aqueous solutions, whereas prepolymer solutions with lower surface tension (Table 1) tend to wet and spread on the entire surface. To address these limitation, Biebuyck and Whitesides utilized a two-phase system consisting of water and an immiscible hydrocarbon fluid, such as hexadecane, to generate microdroplet arrays of hydrocarbons on a patterned self-assembled monolayers (SAMs) on gold substrate to produce an array of polymer micropads. ${ }^{[68]}$ Organization of the hydrophobic prepolymer liquid to fill in hexadecanethiol-modified regions was the consequence of minimization of interfacial free energy when hydrophilic regions were initially occupied by water. In another two-phase system, Yu et al. created highly ordered submicrometer lens arrays by UV-induced polymerization of a 1,6-hexanediol diacrylate nanodroplet array on an immersed and hydrophobic-hydrophilic
Table 1. Surface tensions of some common liquids.

\begin{tabular}{lc}
\hline Liquid & $\sigma\left[\mathrm{mN} \mathrm{m}^{-1}\right]$ \\
\hline Water $\left[20^{\circ} \mathrm{C}\right]^{[142]}$ & 72.2 \\
Ethylene glycol $\left[20^{\circ} \mathrm{C}\right]^{[142]}$ & 47.7 \\
$n$-Hexadecane $\left[20^{\circ} \mathrm{C}\right]^{[142]}$ & 27.5 \\
Acetone $\left[20^{\circ} \mathrm{C}\right]^{[142]}$ & 25.2 \\
Ethanol $\left[20^{\circ} \mathrm{C}\right]^{[142]}$ & 22.1 \\
$n$-Heptane $\left[20^{\circ} \mathrm{C}\right]^{[142]}$ & 20.1 \\
$n$-Hexane $\left[20^{\circ} \mathrm{C}\right]^{[142]}$ & 18.4 \\
Dupont Krytox $\left[26^{\circ} \mathrm{C}\right]^{[143]}$ & $16-20$ \\
Basal medium (no additive) $\left[37^{\circ} \mathrm{C}\right]^{[144]}$ & 69 \\
Basal medium (with 3\% FBS) $\left[37^{\circ} \mathrm{C}\right]^{[144]}$ & 52 \\
\hline
\end{tabular}

patterned substrate. ${ }^{[69]}$ An array of monomer nanodroplets was generated on the hydrophobic domains through a nucleationand-growth process when the good solvent of the monomer above the substrate was gradually displaced by a poor solvent, which was named solvent exchange method. ${ }^{[70-72]}$ The fluid cell was then placed under UV light to transform the liquid nanodroplets into permanent polymer.

Recently, our group introduced a straightforward approach for glass surface patterning that enabled the fabrication of high-density arrays of organic microdroplets with low surface tensions (Figure 7A-C). ${ }^{[73]}$ The chemical modification of a chloro(dimethyl)vinylsilane-coated flat surface with $1 \mathrm{H}, 1 \mathrm{H}, 2 \mathrm{H}, 2 \mathrm{H}$-perfluorodecanethiol (PFDT) endowed the fluorinated regions with remarkable dynamic dewettability even for ethanol and hexane $\left(\gamma_{\mathrm{v}}=18.4 \mathrm{mN} \mathrm{m}^{-1}\right)$. When organic liquid was moved across a PFDT-cysteamine-patterned surface, the liquid dewetted at the PFDT barriers discontinuously and spontaneously formed an array of separated nanodroplets with designed geometries, each located on cysteamine-modified areas (Figure 7A,B). The fabrication of arrays of poly(ethylene dimethacrylate) micropads with features down to $30 \mu \mathrm{m}$ was demonstrated by curing the monomer droplets array under UV (Figure 7C). Since this method does not involve superoleophobic or superhydrophobic structured surfaces, it eliminates the problems of low transparency and complex fabrication and provides substrates with excellent mechanical stability. The limitation of this strategy is, first of all, the requirement of low defect surfaces in order to achieve the dynamic dewettability. Another limitation is the need for low viscosity liquids. Finally, this method only works for low surface tension liquids and is not applicable to aqueous solutions.

For fabricating multiphasic polymer micro- and nanopads on a surface, Kobaku et al. employed a smooth, (heptadecafluoro-1,1,2,2-tetrahydrodecyl)trichlorosilane-coated $\mathrm{TiO}_{2}$ surface patterned with high surface energy domains, which was achieved by irradiating the surface with UV light $(254 \mathrm{~nm})$ through a photomask to trigger the photocatalytic cleavage of the $\mathrm{TiO}_{2}$-silane bond in the designed regions. ${ }^{[20]}$ Polymer solution self-assembled within the high surface energy domains to form droplet arrays during dip coating and the polymer pads were generated after evaporating the solvent. Multiphasic 


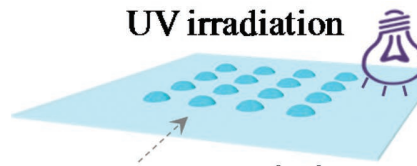

monomer solution microdroplets

B
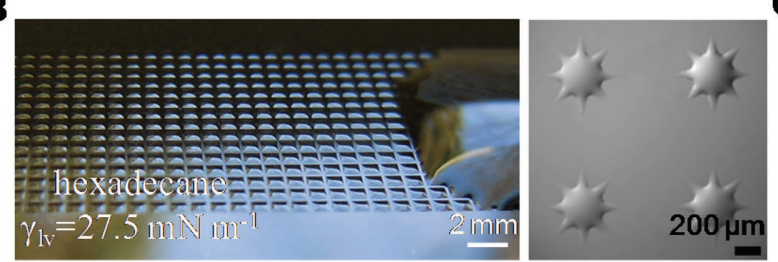

polymer micropads array C

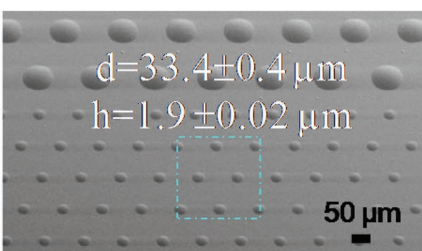

D

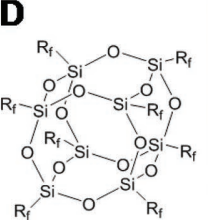

$\mathrm{R}_{\mathrm{f}}=\mathrm{CH}_{2} \mathrm{CH}_{2}\left(\mathrm{CF}_{2}\right)_{7} \mathrm{CF}_{3}$

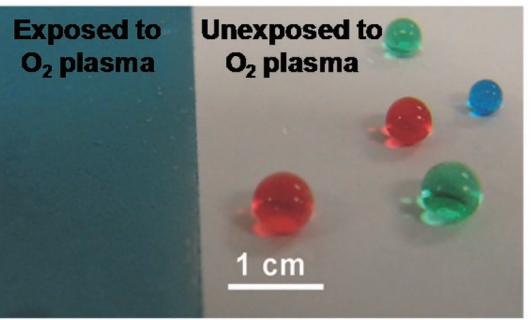

$\mathbf{E}$
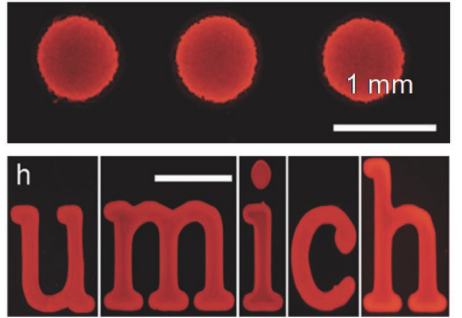

Figure 7. Formation of polymer microarrays via the droplet microarray strategy. A) Schematic showing the UV-induced formation of polymer micropad arrays on a prepatterned glass slide. Liquid monomer is first deposited via discontinuous dewetting to form droplet microarrays with desired geometry and then polymerized under UV light. B) Fabrication of a microdroplet array of hexadecane microdroplets of complex geometries on a prepatterned glass slide via discontinuous dewetting. C) Secondary Electron Microscopy (SEM) image of the produced poly(ethylene dimethacrylate)micropads. Reproduced with permission. ${ }^{[73]}$ Copyright 2016, John Wiley and Sons. D) A photograph showing a surface fabricated by electrospinning a solution of fluorodecyl POSS and PMMA onto a substrate that is exposed (left, superomniphilic) and unexposed (right, superomniphobic) to $\mathrm{O}_{2}$ plasma. E) Site-selective self-assembly of poly(isobutylene) dissolved in heptane using superomniphilic domains of different shapes. Reproduced with permission. ${ }^{[88]}$ Copyright 2012, John Wiley and Sons.

particles with precisely controlled geometry and chemistry were obtained after assembling different polymers or inorganic particles in a layer-by-layer organization.

There are several strategies to detach polymer structures formed on surfaces, if there is no covalent immobilization of the polymer. Thus, Kobaku et al. fabricated freestanding polymer micro- and nanopads upon releasing these multiphasic assemblies from the template by dissolving a predeposited sacrificial layer poly(sodium 4-styrenesulfonate) in water. ${ }^{[20]}$ This also made the templates reusable. It is also possible to detach polymer particles by applying weak mechanical forces using either swelling, washing, or purging strategies.

The method of polymer film dewetting has been used for polymer deposition. ${ }^{[7-77]}$ As an example, a vapor-induced dewetting of SU-8 thin film on hydrophobic-hydrophilic patterned PDMS substrates was reported by $\mathrm{Bi}$ et al. ${ }^{[7]}$ The cyclopentanone vapor broke up the spin-coated SU-8 film where the defect positions existed and initiated dewetting, while dewetted SU-8 droplets spontaneously organized on hydrophilic spots to form well-aligned polymer arrays. Upon miniaturization, these types of methods, based on bottom-up self-assembly driven effects rather than on top-down pipetting into microwells, become important.

During the last few years, several attempts have been made to fabricate surfaces superrepellent even to low surface tension liquids such as oils and alcohols. ${ }^{[78-87]}$ Tuteja and coworkers reported a patterned superomniphobic-superomniphilic surface for the site-selective self-assembly of low surface tension liquids. ${ }^{[88]}$ By electrospinning a solution of $50 \mathrm{wt} \%$ $1 \mathrm{H}, 1 \mathrm{H}, 2 \mathrm{H}, 2 \mathrm{H}$-heptadecafluorodecyl polyhedral oligomeric silsesquioxane (fluorodecyl POSS) and poly(methyl methacrylate) (PMMA) onto substrates, a superomniphobic surface with a highly porous, re-entrant, and bead morphology was fabricated. The superomniphobic surfaces displayed a high advancing contact angle and low contact angle hysteresis for water and various low-surface-tension liquids including heptane. Permanent superomniphilic patterns were obtained by $\mathrm{O}_{2}$ plasma treatment (Figure 7D). By spraying a solution of poly(isobutylene) in heptane onto the micropatterned superomniphobic-superomniphilic surface, the liquid self-assembled into microdroplets within the superomniphilic domains, and arrays of polymer films with different sizes and shapes were formed upon evaporation of the solvent (Figure 7E).

\subsection{Nanoparticle Assembly}

Due to the unique size-dependent properties of nanoparticles, fabrication of nanoparticle arrays with defined dimensions is important for fundamental research as well as industrial applications $^{[89,90]}$ such as chemical sensors ${ }^{[91,92]}$ or high-performance optical or electrical devices. ${ }^{[93,94]}$ On the other hand, creating micropatterns of particles is still challenging, especially for complex 2D geometries and on large areas.

Droplet microarrays can be a powerful alternative to printing techniques used for patterning nanoparticles. A liquid 
containing suspended particles can be first deposited on a patterned substrate to form discrete fluid elements, followed by the evaporation of solvent and formation of a particle pattern. For example, Hancock et al. used hydrophilic-hydrophobic patterned surfaces to shape liquid droplets into complex geometries to further control the deposition of microparticles at microscale. ${ }^{[95]}$ Based on the prediction of the liquid shapes by using finite element simulations, they achieved the desired particle deposition or gradient formation on the predesigned hydrophilic-hydrophobic patterns. To create ordered arrays of particles with high density, discontinuous dewetting on chemically patterned surfaces was used to form droplet microarrays of particle suspensions. ${ }^{[73,96-99]}$ However, this discontinuous dewetting-induced particle aggregation is only compatible with low viscosity liquid suspensions since the substrate would lose its dewettability in the case of viscous liquids. ${ }^{[100]}$ With the aid of hydrophilic/hydrophobic patterned substrates and inkjet printing technology, nanoparticles have been successfully assembled into controllable 3D microstructures with different morphologies. ${ }^{[01-103]}$ In one study, Wu et al. used a hydrophobic silicon wafer with patterned hydrophilic spots and printed microdroplets of a nanoparticle suspension onto the designed locations (Figure 8A)..$^{[103]}$ During solvent evaporation, the three-phase contact line (TCL) was pinned on the hydrophilic

\section{A}

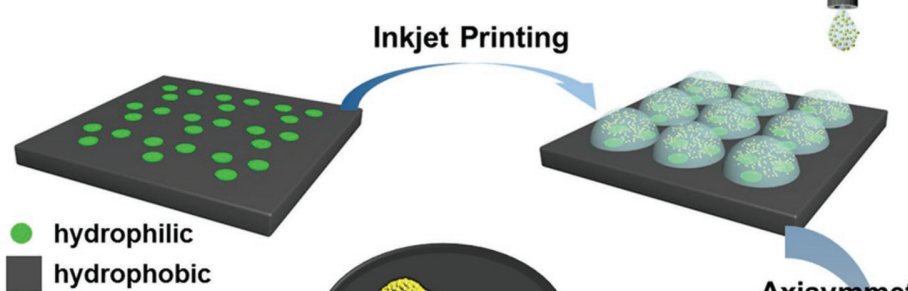
hydrophobic
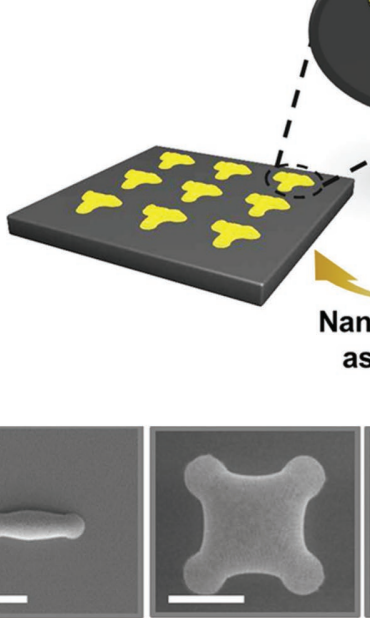
structures
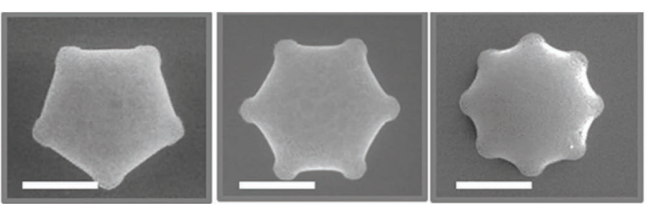

Figure 8. A) Schematic showing the manipulation of the 3D morphology of a microcolloidal crystal pattern via asymmetric dewetting of microdroplets on a hydrophilic-hydrophobic pattern. Nanoparticles contained in droplets are selectively inkjet-printed on a hydrophobic silicon wafer with hydrophilic pinning spots (green shading). As solvent evaporation proceeds, an array of triangle shaped droplets is formed via hydrophilic pattern induced asymmetric dewetting and arrayed 3D microcolloidal crystals with controllable morphology are obtained. B) SEM images showing the morphology manipulation of various assembly units through designed hydrophilic pinning patterns. Scale bar: $20 \mu \mathrm{m}$. Reproduced with permission. ${ }^{[03]}$ Copyright 2015, John Wiley and Sons. regions but retracted on the hydrophobic regions, leading to $3 \mathrm{D}$ structures of closely packed nanoparticles (Figure 8B).

Another route to fabricating highly ordered arrays of nanoparticle is based on the in situ synthesis of nanoparticles in microdroplets. ${ }^{[104-106]}$ This method has been covered in depth in several reviews. ${ }^{[107,108]}$

\subsection{Liquid-Liquid Interfaces}

Liquid-liquid interfaces are extremely important both from the physical chemistry point of view and in various industrial applications, for example, in extraction, catalysis, or colloidal chemistry. ${ }^{[109]}$ Controlling the area and shape of liquid-liquid interfaces is, however, challenging and usually limited to the formation of liquid droplets of various sizes in an immiscible liquid. Arrays of microdroplets with defined shapes forming on wettable-nonwettable surface patterns provide a unique opportunity to precisely control and exploit the liquid-liquid interfacial geometries. Recently, our group demonstrated an interfacial synthesis of freestanding metal-organic framework (MOF) microsheets, HKUST-1 $\left(\mathrm{Cu}_{3} \mathrm{btc} \mathrm{c}_{2}\right)$, with defined size and geometry on superhydrophobic-superhydrophilic patterned surfaces (Figure 9A). ${ }^{[10]}$ This was achieved by first creating an array of copper acetate aqueous microdroplets with defined geometries via discontinuous dewetting, followed by covering the droplet microarrays with a waterimmiscible solution of benzene tricarboxylic acid in 1-octanol. The nucleation and growth of MOFs occurred only at the water-octanol interface, thereby leading to MOF microsheets with geometries defined by that of the wateroctanol interface. Interestingly, the MOF microsheets could be released from the substrate to generate free-standing MOF microsheets of defined geometries (Figure 9B-D).

Inspired by the Nepenthes pitcher plant, slippery liquid-infused porous surfaces (SLIPS) or lubricant-impregnated surfaces are based on the stabilization of a liquid layer by capillary forces within a porous or textured surface. ${ }^{[111-115]}$ This yields a smooth lubricating film that possesses, depending on the lubricant, efficient liquid-repellency and drop mobility, anti-icing properties, stain-resistant properties and antibacterial or biofilm repellent properties. ${ }^{[116-119]}$ The ability to create precise micro- or macropatterns of SLIPS could be used to create novel multifunctional surfaces and significantly expand the scope of possible applications of SLIPS. However, the low surface tension of most of lubricants and oils used for the generation of SLIPS makes it very difficult to create stable SLIPS patterns. To solve this challenge we exploited the ability to spontaneously form aqueous droplet arrays and patterns via discontinuous dewetting on superhydrophobic-hydrophilic surfaces. ${ }^{[120]}$ Since the hydrophilic regions of the porous 

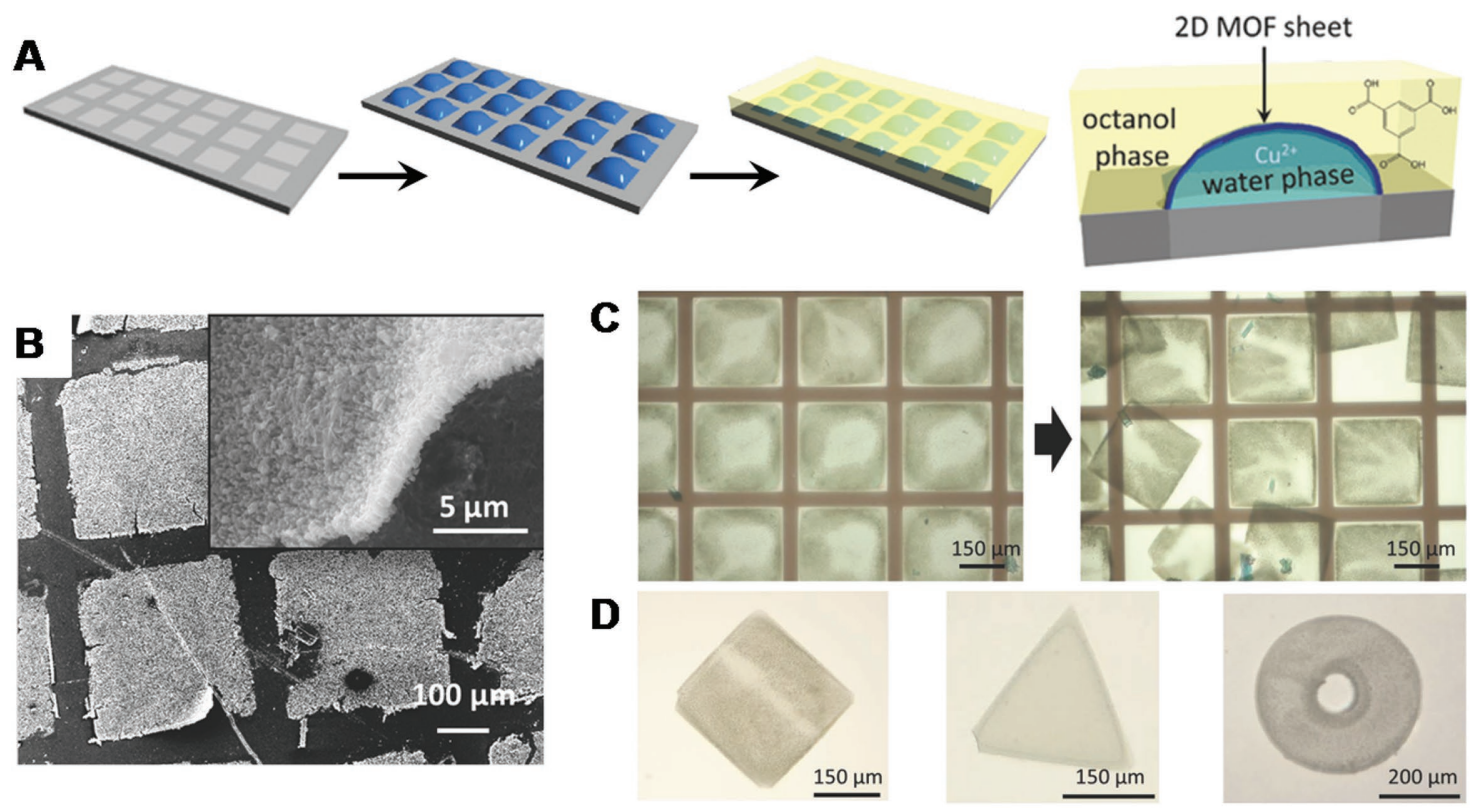

Figure 9. A) Schematic showing the formation of metal organic framework (MOF) microsheets at the spatially confined liquid-liquid interface between water droplet microarrays formed on a superhydrophilic-superhydrophobic micropatterned substrate and water immiscible octanol phase above the water droplets. Right: Basic unit of HKUST-1 growth on an individual water-octanol interface. B) SEM images of patterned MOF superstructures (inset shows the side view on a broken sheet). C) Optical images showing the detachment of the MOF microsheets from the patterned substrate upon rinsing with ethanol. D) Freestanding MOF superstructures with different shapes after transfer on glass microscope slides. Reproduced with permission. ${ }^{[10]}$ Copyright 2016, John Wiley and Sons.

surfaces are occupied by the water droplets, the lubricant only penetrates the dry superhydrophobic areas when it is applied over the entire surface, leading to a stable lubricant-infused pattern surrounded by water-filled porous hydrophilic regions. Such SLIPS micropatterns were applied to form cell micropatterns, ${ }^{[120,121]}$ and biofilm microclusters of different geometries. $^{[122]}$ This relatively straightforward but powerful method can find applications in studies of ice nucleation, cell screenings, biofilm screenings or to study complex biofilm architecture, heterogeneity, and interactions between biofilm subpopulations.

\subsection{Sensor Microchips}

Microdroplets can be useful for (bio)sensor applications, because of the reduced usage of sample and reagents, possibility for in situ analyses, and increased sensitivity due to faster diffusion at the microscale. ${ }^{[123]}$ In this sense, Huang et al. reported a patterned $\mathrm{TiO}_{2}$ surface with high contrast of wettability for forming arrays of droplets containing $\mathrm{FeCl}_{3}, \mathrm{CuSO}_{4}$, $\mathrm{Cd}\left(\mathrm{CH}_{3} \mathrm{COO}\right)_{2}$, and methyl orange to perform qualitative gas sensing by colorimetrical analysis. ${ }^{[124]}$ Due to the high surface areas of the microdroplets for gas contact, the color of droplets containing specific indicators quickly changed when the chip was exposed to $\mathrm{H}_{2} \mathrm{~S}$ and $\mathrm{NH}_{3}$ gas.

The ability to control the composition of individual droplets on a droplet microarray (for an overview of these methods vide infra) allows for the conductance of multiplexed analyses and examination of hundreds to thousands of different sensing molecules in a single experiment. As an example, Qiao et al. designed droplet microarrays on a hydrophilic-superhydrophobic patterned chip to meet the challenge in the detection of low abundance biomolecules. ${ }^{[125]}$ In their study, different types of molecular probes for specific molecular targets were chemically immobilized on individual hydrophilic islands to achieve multiplexed biosensing. Evaporation of $4 \mu \mathrm{L}$ droplets also greatly enriched the concentration of target molecules, enhancing both the reaction speed and the detection sensitivity. This droplet microarray was also utilized for ultrasensitive nucleic acid quantification by the same group. ${ }^{[126]}$

\subsection{Microreactors}

Miniaturization of organic or inorganic synthesis, sample preparation and crystallization processes is very important for various applications ranging from combinatorial synthesis of drug candidates to cell lysis or high-throughput protein crystallization. Currently, most of these processes are performed at the scale of micro- to milliliters, limiting the number of parallel experiments and the maximum total throughput possible. This leads to a related problem that the synthesis of organic molecules is technically disconnected from the final biological application, making high-throughput screenings of compound libraries extremely expensive, time consuming, and inefficient. In order to solve this problem, technologies need to be developed to allow miniaturization and parallelization of such processes. These novel technologies, however, have to be simple, versatile, and should not lead to the generation of additional complexity. Unfortunately, many alternative miniaturized technologies are not compatible with high-throughputs or require completely new automation infrastructures. Droplet microarrays possess 

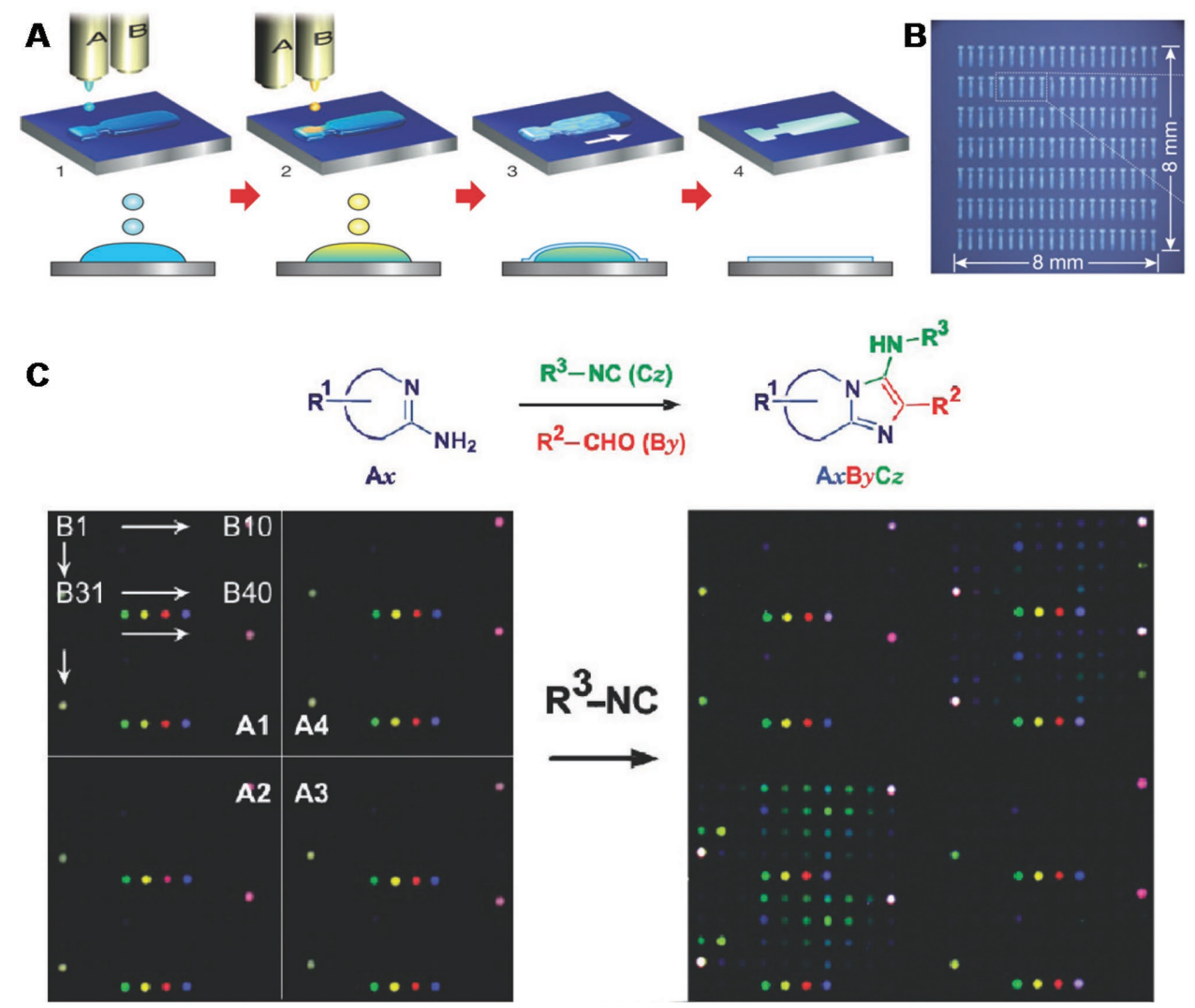

Figure 10. Reactions in droplet microarrays. A) Schematic of the fabrication of organic single-crystal thin films in droplets. On a hydrophobic-hydrophilic patterned silicon wafer, antisolvent ink is first inkjet-printed, and then solution ink is overprinted sequentially to form intermixed droplets confined to a hydrophilic area. Semiconducting thin films grow at liquid-air interfaces of the droplet before the solvent fully evaporates. B) Images of a $20 \times 7$ array of inkjet-printed $\mathrm{C}_{8}$-BTBT single-crystal thin-films. Reproduced with permission. [128] Copyright 2011, Nature Publishing Group. C) Combinatorial synthesis of the fluorophore library by the three-component Ugi reaction (3-CR) within a droplet microarray. Four positional isomers of carboxymethyl2-aminopyridine (A1-A4), 40 positional aldehydes (B1-B40), and cyclohexyl isocyanide (C1) are mixed in arrayed droplets to provide 160 unique combinations. Fluorescence of each droplet with (right) and without (left) exposure to isocyanide vapor is analyzed with a microarray scanner at four different filter settings. Reproduced with permission. ${ }^{[130]}$ Copyright 2011, American Chemical Society.

properties that can potentially solve these problems by permitting highly parallel and miniaturized (down to femtoliters) processes, such as synthesis, extractions, and crystallizations.

Thus, Shi et al. presented a total RNA extraction droplet array to perform parallel RNA extractions on a droplet array. ${ }^{[127]}$ Minemawari et al. produced patterned organic semiconducting 2,7-dioctyl[1]benzothieno[3,2-b][1]benzothiophene $\quad\left(\mathrm{C}_{8}\right.$-BTBT) thin films of high crystallinity through antisolvent crystallization at the liquid-air interfaces of droplet microarrays, illustrating a way of producing surface transistor arrays ${ }^{[28]}$ (Figure 10A,B). Interestingly, the droplet geometries played an essential role for the crystallinity of the formed films. Mugherli et al. utilized droplet arrays to synthesize and profile new enzyme inhibitors of the NS3/4A serine protease of the hepatitis $\mathrm{C}$ virus. ${ }^{[129]}$ Two hundred hydrazides were dispensed onto a hydrophobic-hydrophilic substrate in order to enable the synthesis of 20100 distinct dihydrazones inside the droplets. The reactions in droplet arrays on this planar solid surface exhibited high cost-efficiency in that reagent consumption was $\approx 1000$ times lower than in microtiter plates. Combinatorial synthesis and screening of autofluorescent drug-like molecules in droplet microarrays were reported by Burchak et al. ${ }^{[130]}$ Assembly of different components in arrayed droplets provided 1600 unique combinations, and the fluorescence of each droplet was analyzed in situ with a microarray scanner (Figure 10C), exemplifying the feasibility of combinatorial synthesis and screening of chemical libraries in droplet microarrays.

\section{Parallel Addition of Compound Libraries to Droplet Microarrays}

As discussed above, chemical or biological (ultra) highthroughput screenings are one of the main future applications of droplet microarray platforms. In complex assays or multicomponent experiments, however, different (bio)chemical agents need to be added into individual liquid droplets. In this section, we discuss several existing and proposed strategies for the addition of different chemicals to individual microdroplets.

Addition of chemicals to arrayed droplets via absorption from the gas phase is one of the simplest methods. Burchak et al., for example, added volatile isocyanides to the arrayed aminopyridine 


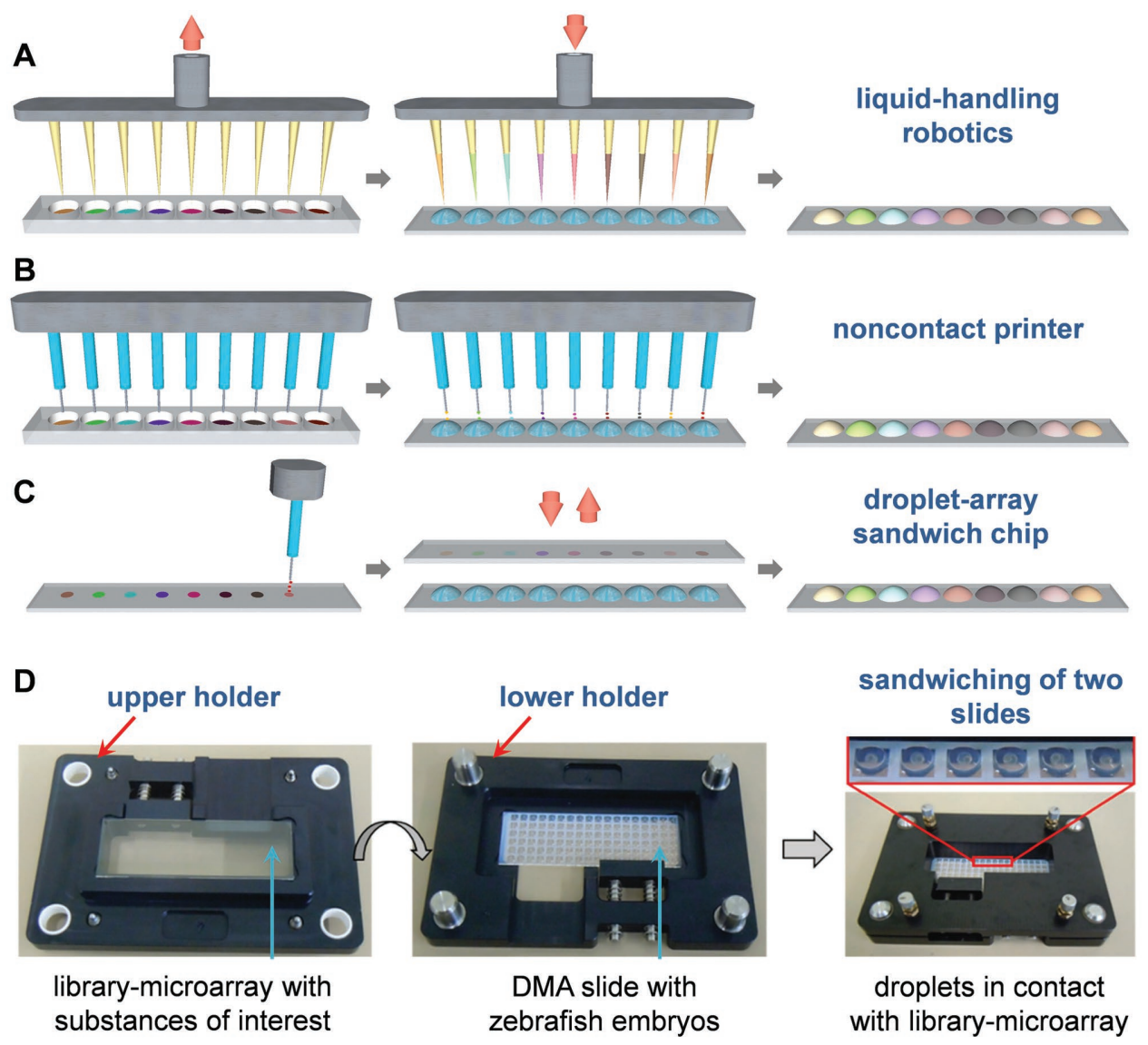

Figure 11. Schematic showing the parallel addition of (bio)chemical reagents into droplet microarrays via different strategies: A) liquid-handling robotics; B) noncontact printer; and C) droplet-array sandwich chip. D) Photographs of the handheld device used for aligning the droplets microarray when manipulating individual droplets using the sandwiching method. Reproduced with permission. ${ }^{[141]}$ Copyright 2017, John Wiley and Sons.

aldehyde mixtures by placing the whole array into a chamber saturated with isocyanide vapor, thus avoiding the need to dispense these compounds one by one. ${ }^{[130]}$ This strategy offers a noncontact, cross contamination-free chemical addition to all droplets in a single step, independent of the size and density of the droplets. The disadvantage is, however, that only a single, volatile component can be added to all the droplets in parallel.

Dedicated liquid-handling robots have been widely applied in life science laboratories for pipetting purposes (Figure 11A). ${ }^{[131]}$ Since the majority of automatic liquid-handling robots are compatible with 96- and 384-well microtiter plates, pipetting heads are usually designed with 96 or 384 channels and with dispensing volume ranging from $100 \mathrm{~nL}$ to $1000 \mu \mathrm{L}$. There are also several contact- and noncontact printing methods using, for example, pin-based printers, piezoelectric, or pressuredriven dispensers, that allow for parallel dispensing of pico-tonanoliter droplets with good X-Y precision (Figure 11B).

Recently, our group reported a droplet microarray "sandwiching" technology to enable the single-step addition of different (bio)chemicals into individual microdroplets on planar substrates. ${ }^{[132]}$ The method is schematically shown in Figure 11C,D. First, a library-microarray slide is prepared by printing compounds of interest in an array format on a glass slide. Precise alignment and "sandwiching" of the droplet microarray slide containing chemicals ${ }^{[67,73,133]}$ or cells ${ }^{[42,134]}$ with the library-microarray slide face-to-face leads to the dissolution of the chemicals in the individual microdroplets without any crosscontamination between adjacent droplets (Figure 11C). The advantage of this method is that after preprinting a library-microarray using a conventional noncontact printer, the final addition of chemical libraries to the droplets can be done with a very simple handheld device (Figure 11D). ${ }^{[135]}$ The same sandwiching device can be used to perform other parallel treatments, for example, staining, fixation, or lysis of cells in the individual droplets. A similar method of high-density chip-tochip reagent transfer was reported by the group of Juncker. ${ }^{[136]}$ Nevertheless, the kinetics of the reagent transfer using the sandwiching approach depends on the solubility of reagents in the final solvent. Another challenge is that $50 \%$ of the volume will stay on the library microarray slide after the sandwiching.

\section{Summary and Outlook}

Parallelization and miniaturization of experiments are fundamentally important in biology, chemistry, the pharmaceutical 
industry, biotechnology, medicine, and diagnostics. Miniaturization can significantly accelerate the analysis and reduce the costs of various experiments including cell and chemical screenings or diagnostic applications. Currently, most screenings worldwide are performed using either 96- or 384-well microplates, resulting in huge consumption of reagents, chemicals, cells, and associated consumables. The microplate technology also greatly relies on expensive automation systems, which are not always affordable for research laboratories. Further miniaturization of microplates by reducing the size of the wells in the plastic plates is not a solution as the capillary forces and surface tension become more and more important in smaller wells making the liquid handling more and more challenging. An elegant solution, instead, would be to use the capillary forces and surface tension to control the positions of microdroplets on flat surfaces prepatterned with arrays of wettable spots separated by liquidrepellent regions. This approach is used in the growing field of droplet microarrays. Apart from the inherent capability of miniaturization down to pico or nanoliters, droplet microarrays benefit from the effect of discontinuous dewetting, which is driven by the self-organization of a liquid on the pattern of different surface energies to spontaneously form an array of smaller droplets. Thus, the formation of thousands of microdroplets in this case does not necessarily require thousands of pipetting steps.

The development of droplet microarrays, however, requires the ability to control both the chemical properties and surface topography in precise spatial patterns. The choice of substrate material, surface coating, surface chemistry, porosity of the coating, surface topography, and geometry or size of the produced patterns are important for achieving correct functionality of the produced arrays. All these parameters influence special wettability (e.g., superhydrophobicity, superoleophobicity, omniphobicity, oleophilicity, dewettability, etc.), transparency, stability, biocompatibility, and compatibility of the surfaces, and arrays with the final application. Thus, generation of practically useful droplet microarrays is a challenging task that requires the development of novel functional materials, surfaces, and methods for surface functionalization and patterning.

Other challenges include the ability to create thousands of isolated droplets with reproducible and identical volumes, which is not a trivial task because the droplet volumes depend on many factors including surface tension of the solution, geometry of the hydrophilic spots, the way the solution is applied, ${ }^{[137]}$ humidity, the presence of surface defects, etc. Nevertheless, by controlling these parameters it is possible to reduce the volume variability. Thus, even manual formation of isolated droplets on hydrophilic-superhydrophobic patterned surfaces by discontinuous dewetting leads only to about $5 \%$ variability for droplets of $11.5 \mathrm{~nL}^{[42 \mathrm{~b}]}$ This variability can be further improved by standardizing the method for the droplet formation including the size of the "mother droplet" and the spreading speed as well as by reducing the number of any surface defects that might lead to heterogeneity.

Another challenge is that with the decrease of their size, droplets become more sensitive to evaporation, a common issue when handling small liquid volumes. ${ }^{[138]}$ For instance, a $10 \mathrm{~nL}$ drop evaporates in 10-30 $\mathrm{s}$ and the evaporation of a picoliter droplet can take less than $1 \mathrm{~s}$ under ambient conditions. ${ }^{[13]}$ There are two main effective ways to avoid fast droplet evaporation. Covering droplets with an oil (e.g., mineral oil, silicone oil, or a perfluoro oil) can effectively stop or significantly reduce the speed of evaporation. Another straightforward way is to increase local humidity by placing the array into a closed environment with controlled humidity and/or by placing sacrificial water around the droplets of interest.

Despite the existing challenges, the studies described in this Progress Report clearly indicate that the ability to create arrays of droplets of various sizes and volumes from picoliters to microliters in precise locations on flat surfaces defines a revolutionary leap in technology for drug discovery, combinatorial synthesis, and personalized medicine. The openness of the droplet microarray systems largely facilitates high-throughput analytical assays, such as mass-spectrometry or other spectroscopy analyses, as well as the ability of parallel addition of thousands of components to the individual nanodroplets using different established and emerging technologies. The reduced usage of sample and reagents, possibility for in situ analyses, higher sensitivity, and single-step formation of high-density droplet arrays allow this technique to be suitable for point-ofcare and diagnostics applications. ${ }^{[139]}$

With the very fast growth in the field of droplet arrays recently, numerous new methods have been developed that are applicable for aqueous solutions, including cell suspensions, as well as for low surface tension organic solvents. The former clear the way to a diverse spectrum of biologically relevant applications, such as cell screenings, stem cell screenings, single cell applications, cell spheroid screenings, hydrogel patterning, biochemical screenings, or even full animal (e.g., zebrafish) screenings. ${ }^{[140,141]}$ The latter open the possibility to perform organic synthesis in pico to microliter droplets in parallel. High-throughput screenings of catalysts, polymer synthesis, drug library screenings, synthesis of transfection reagents, and nanoparticle synthesis are all imaginable potential applications. Although numerous challenges remain in the development of droplet microarrays, we expect to see that the presented progress in this field with the impressive number of potential advantages will continue to lead to scientific and industrial advances.

\section{Acknowledgements}

This work was supported by the European Research Council (ERC) Starting Grant (ID: 337077-DropCellArray), Helmholtz Association's Initiative and Networking Fund (Grant No. VH-NG-621). We thank Maximilian Benz for a photograph for the ToC image.

\section{Keywords}

high-throughput screening, microarrays, microfluidics, miniaturization, superhydrophobicity 
[1] A. Huebner, S. Sharma, M. Srisa-Art, F. Hollfelder, J. B. Edel, A. J. Demello, Lab Chip 2008, 8, 1244.

[2] M. Kansy, F. Senner, K. Gubernator, J. Med. Chem. 1998, 41, 1007.

[3] T.-K. Jenssen, A. Laegreid, J. Komorowski, E. Hovig, Nat. Genet. 2001, 28, 21.

[4] D. T. Chiu, R. M. Lorenz, G. D. M. Jeffries, Anal. Chem. 2009, 81, 5111.

[5] S.-Y. Teh, R. Lin, L.-H. Hung, A. P. Lee, Lab Chip 2008, 8, 198.

[6] D. Mark, S. Haeberle, G. Roth, F. von Stetten, R. Zengerle, Chem. Soc. Rev. 2010, 39, 1153.

[7] R. R. Pompano, W. S. Liu, W. B. Du, R. F. Ismagilov, Annu. Rev. Anal. Chem. 2011, 4, 59.

[8] H. Song, J. D. Tice, R. F. Ismagilov, Angew. Chem., Int. Ed. 2003, $42,768$.

[9] A. B. Theberge, F. Courtois, Y. Schaerli, M. Fischlechner, C. Abell, F. Hollfelder, W. T. S. Huck, Angew. Chem., Int. Ed. 2010, 49, 5846.

[10] L. M. Mayr, D. Bojanic, Curr. Opin. Pharmacol. 2009, 9, 580.

[11] R. Kittler, G. Putz, L. Pelletier, I. Poser, A.-K. Heninger, D. Drechsel, S. Fischer, I. Konstantinova, B. Habermann, H. Grabner, M.-L. Yaspo, H. Himmelbauer, B. Korn, K. Neugebauer, M. T. Pisabarro, F. Buchholz, Nature 2004, 432, 1036.

[12] L. Pelkmans, E. Fava, H. Grabner, M. Hannus, B. Habermann, E. Krausz, M. Zerial, Nature 2005, 436, 78.

[13] R. J. Jackman, D. C. Duffy, E. Ostuni, N. D. Willmore, G. M. Whitesides, Anal. Chem. 1998, 70, 2280.

[14] V. R. Thalladi, G. M. Whitesides, J. Am. Chem. Soc. 2002, 124, 3520.

[15] M. Margulies, M. Egholm, W. E. Altman, S. Attiya, J. S. Bader, L. A. Bemben, J. Berka, M. S. Braverman, Y.-J. Chen, Z. Chen, S. B. Dewell, L. Du, J. M. Fierro, X. V. Gomes, B. C. Godwin, W. He, S. Helgesen, C. H. Ho, G. P. Irzyk, S. C. Jando, M. L. I. Alenquer, T. P. Jarvie, K. B. Jirage, J.-B. Kim, J. R. Knight, J. R. Lanza, J. H. Leamon, S. M. Lefkowitz, M. Lei, J. Li, K. L. Lohman, H. Lu, V. B. Makhijani, K. E. McDade, M. P. McKenna, E. W. Myers, E. Nickerson, J. R. Nobile, R. Plant, B. P. Puc, M. T. Ronan, G. T. Roth, G. J. Sarkis, J. F. Simons, J. W. Simpson, M. Srinivasan, K. R. Tartaro, A. Tomasz, K. A. Vogt, G. A. Volkmer, S. H. Wang, Y. Wang, M. P. Weiner, P. Yu, R. F. Begley, J. M. Rothberg, Nature 2005, 437, 376.

[16] W. Du, L. Li, K. P. Nichols, R. F. Ismagilov, Lab Chip 2009, 9, 2286.

[17] L. Ma, S. S. Datta, M. A. Karymov, Q. Pan, S. Begolo, R. F. Ismagilov, Integr. Biol. 2014, 6, 796.

[18] J. D. Hoheisel, Nat. Rev. Genet. 2006, 7, 200.

[19] M. J. Heller, Annu. Rev. Biomed. Eng. 2002, 4, 129.

[20] S. P. R. Kobaku, G. Kwon, A. K. Kota, R. G. Karunakaran, P. Wong, D. H. Lee, A. Tuteja, ACS Appl. Mater. Interfaces 2015, 7, 4075.

[21] E. Ueda, F. L. Geyer, V. Nedashkivska, P. A. Levkin, Lab Chip 2012, 12, 5218.

[22] G. Piret, E. Galopin, Y. Coffinier, R. Boukherroub, D. Legrand, C. Slomianny, Soft Matter 2011, 7, 8642.

[23] H. Liu, Z. Yang, L. Meng, Y. Sun, J. Wang, L. Yang, J. Liu, Z. Tian, J. Am. Chem. Soc. 2014, 136, 5332.

[24] B. Bao, J. Sun, M. Gao, X. Zhang, L. Jiang, Y. Song, Nanoscale 2016, 8, 9556

[25] H. J. Zhang, T. Oellers, W. Q. Feng, T. Abdulazim, E. N. Saw, A. Ludwig, P. A. Levkin, N. Plumere, Anal. Chem. 2017, 89, 5833.

[26] M. T. Dulay, L. S. Eberlin, R. N. Zare, Anal. Chem. 2015, 87, 12324.

[27] S. K. Küster, S. R. Fagerer, P. E. Verboket, K. Eyer, K. Jefimovs, R. Zenobi, P. S. Dittrich, Anal. Chem. 2013, 85, 1285.

[28] S. K. Küster, M. Pabst, R. Zenobi, P. S. Dittrich, Angew. Chem., Int. Ed. 2015, 54, 1671.

[29] S. K. Küster, M. Pabst, K. Jefimovs, R. Zenobi, P. S. Dittrich, Anal. Chem. 2014, 86, 4848 .
[30] W. F. An, N. Tolliday, Mol. Biotechnol. 2010, 45, 180.

[31] I. Banerjee, R. C. Pangule, R. S. Kane, Adv. Mater. 2011, 23, 690.

[32] M.-Y. Tsai, C.-Y. Lin, C.-H. Huang, J.-A. Gu, S.-T. Huang, J. Yu, H.-Y. Chen, Chem. Commun. 2012, 48, 10969.

[33] T. Tischer, C. Rodriguez-Emmenegger, V. Trouillet, A. Welle, V. Schueler, J. O. Mueller, A. S. Goldmann, E. Brynda, C. Barner-Kowollik, Adv. Mater. 2014, 26, 4087.

[34] C. Rodriguez-Emmenegger, C. M. Preuss, B. Yameen, O. Pop-Georgievski, M. Bachmann, J. O. Mueller, M. Bruns, A. S. Goldmann, M. Bastmeyer, C. Barner-Kowollik, Adv. Mater. 2013, 25, 6123 .

[35] T. Ishizaki, N. Saito, O. Takai, Langmuir 2010, 26, 8147.

[36] F. L. Geyer, E. Ueda, U. Liebel, N. Grau, P. A. Levkin, Angew. Chem., Int. Ed. 2011, 50, 8424.

[37] J. Li, L. Li, X. Du, W. Feng, A. Welle, O. Trapp, M. Grunze, M. Hirtz, P. A. Levkin, Nano Lett. 2015, 15, 675.

[38] W. Feng, L. Li, C. Yang, A. Welle, O. Trapp, P. A. Levkin, Angew. Chem., Int. Ed. 2015, 54, 8732.

[39] E. Ueda, W. Feng, P. A. Levkin, Adv. Healthcare Mater. 2016, 5, 2646.

[40] F. L. Geyer, E. Ueda, U. Liebel, N. Grau, P. A. Levkin, Angew. Chem., Int. Ed. 2011, 50, 8424

[41] A. N. Efremov, E. Stanganello, A. Welle, S. Scholpp, P. A. Levkin, Biomaterials 2013, 34, 1757.

[42] a) A. A. Popova, K. Demir, T. G. Hartanto, E. Schmitt, P. A. Levkin, RSC Adv. 2016, 6, 38263. b) B. Chang, Q. Zhou, R. H. A. Ras, A. Shah, Z. Wu, K. Hjort, Appl. Phys. Lett. 2016, 108, 154102.

[43] W. Feng, L. Li, E. Ueda, J. Li, S. Heißler, A. Welle, O. Trapp, P. A. Levkin, Adv. Mater. Interfaces 2014, 1, 1400269.

[44] E. Ueda, P. A. Levkin, Adv. Mater. 2013, 25, 1234.

[45] T. Tronser, A. A. Popova, P. A. Levkin, Curr. Opin. Biotechnol. 2017, 46, 141.

[46] Y. Y. Lee, K. Narayanan, S. J. Gao, J. Y. Ying, Nano Today 2012, 7, 29.

[47] T. Tronser, A. A. Popova, M. Jaggy, M. Bastmeyer, P. A. Levkin, Adv. Healthcare Mater. 2017, 6, 1700622.

[48] M. Jaggy, P. Zhang, A. M. Greiner, T. J. Autenrieth, V. Nedashkivska, A. N. Efremov, C. Blattner, M. Bastmeyer, P. A. Levkin, Nano Lett. 2015, 15, 7146.

[49] A. Author, Lab Chip 2007, 7, 544.

[50] L. Armbrecht, P. S. Dittrich, Anal. Chem. 2017, 89, 2.

[51] D. Hummer, F. Kurth, N. Naredi-Rainer, P. S. Dittrich, Lab Chip 2016, 16, 447.

[52] Y. Zhu, Y.-X. Zhang, W.-W. Liu, Y. Ma, Q. Fang, B. Yao, Sci. Rep. 2015, 5, 9551.

[53] H. Li, Q. Yang, G. Li, M. Li, S. Wang, Y. Song, ACS Appl. Mater. Interfaces 2015, 7, 9060

[54] G. E. Jogia, T. Tronser, A. A. Popova, P. A. Levkin, Microarrays 2016, $5,28$.

[55] J. Holtfreter, J. Exp. Zool. 1944, 95, 171.

[56] A. Moscona, H. Moscona, J. Anat. 1952, 86, 287.

[57] J. M. Kelm, N. E. Timmins, C. J. Brown, M. Fussenegger, L. K. Nielsen, Biotechnol. Bioeng. 2003, 83, 173.

[58] R.-Z. Lin, H.-Y. Chang, Biotechnol. J. 2008, 3, 1172.

[59] S. Breslin, L. O'Driscoll, Drug Discovery Today 2013, 18, 240.

[60] Y. C. Tung, A. Y. Hsiao, S. G. Allen, Y. S. Torisawa, M. Ho, S. Takayama, Analyst 2011, 136, 473

[61] A. I. Neto, C. R. Correia, C. A. Custódio, J. F. Mano, Adv. Funct. Mater. 2014, 24, 5096.

[62] A. I. Neto, C. R. Correia, M. B. Oliveira, M. I. Rial-Hermida, C. Alvarez-Lorenzo, R. L. Reis, J. F. Mano, Biomater. Sci. 2015, 3, 581.

[63] M. B. Oliveira, A. I. Neto, C. R. Correia, M. I. Rial-Hermida, C. Alvarez-Lorenzo, J. F. Mano, ACS Appl. Mater. Interfaces 2014, 6, 9488 . 
[64] C. L. Salgado, M. B. Oliveira, J. F. Mano, Integr. Biol. 2012, 4, 318.

[65] H. Li, R. F. Leulmi, D. Juncker, Lab Chip 2011, 11, 528.

[66] Y. Li, P. Chen, Y. Wang, S. Yan, X. Feng, W. Du, S. A. Koehler, U. Demirci, B.-F. Liu, Adv. Mater. 2016, 28, 3543.

[67] A. I. Neto, K. Demir, A. A. Popova, M. B. Oliveira, J. F. Mano, P. A. Levkin, Adv. Mater. 2016, 28, 7613.

[68] H. A. Biebuyck, G. M. Whitesides, Langmuir 1994, 10, 2790.

[69] H. Yu, S. Peng, L. Lei, J. Zhang, T. L. Greaves, X. Zhang, ACS Appl. Mater. Interfaces 2016, 8, 22679

[70] L. Bao, A. R. Rezk, L. Y. Yeo, X. Zhang, Small 2015, 11, 4850.

[71] S. Peng, B.-E. Pinchasik, H. Hao, H. Möhwald, X. Zhang, J. Phys. Chem. Lett. 2017, 8, 584.

[72] X. Zhang, Z. Lu, H. Tan, L. Bao, Y. He, C. Sun, D. Lohse, Proc. Natl. Acad. Sci. USA 2015, 112, 9253.

[73] W. Feng, L. Li, X. Du, A. Welle, P. A. Levkin, Adv. Mater. 2016, 28 , 3202.

[74] A. M. Higgins, R. A. L. Jones, Nature 2000, 404, 476.

[75] P. Sachan, M. Kulkarni, A. Sharma, Langmuir 2015, 31, 12505.

[76] F. Wang, P. Li, D. Wang, L. Li, S. Xie, L. Liu, Y. Wang, W. J. Li, Sci. Rep. 2014, 4, 6524.

[77] X. Bi, W. Li, J. Mater. Chem. C 2015, 3, 5825.

[78] A. Tuteja, W. Choi, M. Ma, J. M. Mabry, S. A. Mazzella, G. C. Rutledge, G. H. McKinley, R. E. Cohen, Science 2007, 318, 1618.

[79] X. Deng, L. Mammen, H. J. Butt, D. Vollmer, Science 2012, $335,67$.

[80] T. L. Liu, C.-J. C. Kim, Science 2014, 346, 1096.

[81] H. Wang, Y. Xue, J. Ding, L. Feng, X. Wang, T. Lin, Angew. Chem., Int. Ed. 2011, 50, 11433.

[82] Y.-K. Lai, Y.-X. Tang, J.-Y. Huang, F. Pan, Z. Chen, K.-Q. Zhang, H. Fuchs, L.-F. Chi, Sci. Rep. 2013, 3, 3009.

[83] K. Golovin, D. H. Lee, J. M. Mabry, A. Tuteja, Angew. Chem., Int. Ed. 2013, 52, 13007.

[84] J. Zhang, S. Seeger, Angew. Chem., Int. Ed. 2011, 50, 6652.

[85] G. Hayase, K. Kanamori, G. Hasegawa, A. Maeno, H. Kaji, K. Nakanishi, Angew. Chem., Int. Ed. 2013, 52, 10788.

[86] S. Pan, A. K. Kota, J. M. Mabry, A. Tuteja, J. Am. Chem. Soc. 2013, 135, 578.

[87] J. Yong, F. Chen, Q. Yang, J. Huo, X. Hou, Chem. Soc. Rev. 2017, 46, 4168.

[88] S. P. R. Kobaku, A. K. Kota, D. H. Lee, J. M. Mabry, A. Tuteja, Angew. Chem., Int. Ed. 2012, 51, 10109.

[89] D. Xia, Z. Ku, D. Li, S. R. J. Brueck, Chem. Mater. 2008, 20, 1847.

[90] X. Ye, L. Qi, Nano Today 2011, 6, 608.

[91] L. Wang, J. Wang, Y. Huang, M. Liu, M. Kuang, Y. Li, L. Jiang, Y. Song, J. Mater. Chem. 2012, 22, 21405.

[92] L. Bai, Z. Y. Xie, W. Wang, C. W. Yuan, Y. J. Zhao, Z. D. Mu, Q. F. Zhong, Z. Z. Gu, ACS Nano 2014, 8, 11094.

[93] Z. Tang, N. A. Kotov, Adv. Mater. 2005, 17, 951.

[94] B. Su, C. Zhang, S. Chen, X. Zhang, L. Chen, Y. Wu, Y. Nie, X. Kan, Y. Song, L. Jiang, Adv. Mater. 2014, 26, 2501.

[95] M. J. Hancock, F. Yanagawa, Y.-H. Jang, J. He, N. N. Kachouie, H. Kaji, A. Khademhosseini, Small 2012, 8, 393.

[96] F. Q. Fan, K. J. Stebe, Langmuir 2004, 20, 3062.

[97] N. Vogel, M. Retsch, C.-A. Fustin, A. del Campo, U. Jonas, Chem. Rev. 2015, 115, 6265.

[98] Y. Masuda, T. Itoh, K. Koumoto, Langmuir 2005, 21, 4478.

[99] S. G. Rao, A. Karim, J. Schwartz, N. Antler, T. Schenkel, I. Siddiqi, ACS Appl. Mater. Interfaces 2014, 6, 12893.

[100] J. Ziegler, J. H. Snoeijer, J. Eggers, Eur. Phys. J.: Spec. Top. 2009, 166, 177.

[101] Y. Huang, W. Li, M. Qin, H. Zhou, X. Zhang, F. Li, Y. Song, Small 2017, 13, 1613

[102] J. Wang, Y. Zhang, S. Wang, Y. Song, L. Jiang, Acc. Chem. Res. $2011,44,405$
[103] L. Wu, Z. Dong, M. Kuang, Y. Li, F. Li, L. Jiang, Y. Song, Adv. Funct. Mater. 2015, 25, 2237.

[104] Z. Zhong, B. Gates, Y. Xia, D. Qin, Langmuir 2000, 16, 10369.

[105] D. Qin, Y. Xia, B. Xu, H. Yang, C. Zhu, G. M. Whitesides, Adv. Mater. 1999, 11, 1433.

[106] M. Abulikemu, E. H. Da'as, H. Haverinen, D. Cha, M. A. Malik, G. E. Jabbour, Angew. Chem. 2014, 53, 420.

[107] A. Kumar, N. L. Abbott, H. A. Biebuyck, E. Kim, G. M. Whitesides, Acc. Chem. Res. 1995, 28, 219.

[108] Y. Xia, D. Qin, Y. Yin, Curr. Opin. Colloid Interface Sci. 2001, 6, 54.

[109] C. N. R. Rao, K. P. Kalyanikutty, Acc. Chem. Res. 2007, 41, 489.

[110] M. Tsotsalas, H. Maheshwari, S. Schmitt, S. Heißler, W. Feng, P. A. Levkin, Adv. Mater. Interfaces 2016, 3, 1500392

[111] D. Quéré, Rep. Prog. Phys. 2005, 68, 2495;

[112] T.-S. Wong, S. H. Kang, S. K. Y. Tang, E. J. Smythe, B. D. Hatton, A. Grinthal, J. Aizenberg, Nature 2011, 477, 443;

[113] J. D. Smith, R. Dhiman, K. Varanasi, 64th Annu. Meet. APS Div. Fluid Dyn. 2011, 56, S4.00001.

[114] A. Lafuma, D. Quéré, EPL Europhys. Lett. 2011, 96, 56001.

[115] B. R. Solomon, S. B. Subramanyam, T. A. Farnham, K. S. Khalil, S. Anand, K. K. Varanasi, in Non-Wettable Surfaces: Theory, Preparation and Applications (Eds: R. Ras, A. Marmur), RSC Publishing, London 2017, Ch. 10.

[116] P. Kim, T.-S. Wong, J. Alvarenga, M. J. Kreder, W. E. Adorno-Martinez, J. Aizenberg, ACS Nano 2012, 6, 6569.

[117] a) A. K. Epstein, T.-S. Wong, R. A. Belisle, E. M. Boggs, J. Aizenberg, Proc. Natl. Acad. Sci. USA 2012, 109, 13182. b) L. Xiao, J. Li, S. Mieszkin, A. Di Fino, A. S. Clare, M. E. Callow, J. A. Callow, M. Grunze, A. Rosenhahn, P. A. Levkin, ACS Appl. Mater. Interfaces 2013, 5, 10074.

[118] X. Tian, S. Shaw, K. R. Lind, L. Cademartiri, Adv. Mater. 2016, 28 , 3677.

[119] N. Vogel, R. A. Belisle, B. Hatton, T. S. Wong, J. Aizenberg, Nat. Commun. 2013, 4, 2176

[120] E. Ueda, P. A. Levkin, Adv. Healthcare Mater. 2013, 2, 1425.

[121] W. Shi, T. Xu, L.-P. Xu, Y. Chen, Y. Wen, X. Zhang, S. Wang, Nanoscale 2016, 8, 18612.

[122] J. Bruchmann, I. Pini, T. S. Gill, T. Schwartz, P. A. Levkin, Adv. Healthcare Mater. 2017, 6, 1601082.

[123] G. Arrabito, B. Pignataro, Anal. Chem. 2012, 84, 5450.

[124] J.-Y. Huang, Y.-K. Lai, F. Pan, L. Yang, H. Wang, K.-Q. Zhang, H. Fuchs, L.-F. Chi, Small 2014, 10, 4865.

[125] W. Qiao, T. Zhang, T. Yen, T.-H. Ku, J. Song, I. Lian, Y. H. Lo, Annu. Biomed. Eng. 2014, 42, 1932.

[126] T. M. Yen, T. T. Zhang, P. W. Chen, T. H. Ku, Y. J. Chiu, I. Lian, Y. H. Lo, ACS Nano 2015, 9, 10655.

[127] X. Shi, C.-H. Chen, W. Gao, S.-H. Chao, D. R. Meldrum, Lab Chip 2015, 15, 1059 .

[128] H. Minemawari, T. Yamada, H. Matsui, J. Tsutsumi, S. Haas, R. Chiba, R. Kumai, T. Hasegawa, Nature 2011, 475, 364.

[129] L. Mugherli, O. N. Burchak, L. A. Balakireva, A. Thomas, F. Chatelain, M. Y. Balakirev, Angew. Chem., Int. Ed. 2009, 48, 7639.

[130] O. N. Burchak, L. Mugherli, M. Ostuni, J. J. Lacapère, M. Y. Balakirev, J. Am. Chem. Soc. 2011, 133, 10058.

[131] F. Kong, L. Yuan, Y. F. Zheng, W. Chen, J. Lab. Autom. 2012, 17, 169.

[132] A. A. Popova, S. M. Schillo, K. Demir, E. Ueda, A. Nesterov-Mueller, P. A. Levkin, Adv. Mater. 2015, 27, 5217.

[133] P. Beyazkilic, U. Tuvshindorj, A. Yildirim, C. Elbuken, M. Bayindir, RSC Adv. 2016, 6, 80049.

[134] K. Xu, X. Wang, R. M. Ford, J. P. Landers, Anal. Chem. 2016, 88, 2652.

[135] A. A. Popova, C. Depew, K. M. Permana, A. Trubitsyn, R. Peravali, I. Á. G. Ordiano, M. Reischl, P. A. Levkin, SLAS Technol. 2017, 22, 163.

[136] H. Li, J. D. Munzar, A. Ng, D. Juncker, Sci. Rep. 2015, 5, 11688. 
[137] N. K. Mandsberg, O. Hansen, R. Taboryski, Sci. Rep. 2017, 7, 12794.

[138] E. Berthier, J. Warrick, H. Yub, D. J. Beebe, Lab Chip 2008, 8, 852.

[139] C.-C. Hong, P.-H. Chang, C.-C. Lin, C.-L. Hong, Biosens. Bioelectron. 2010, 25, 2058.

[140] J. Giacomotto, L. Ségalat, Br. J. Pharmacol. 2010, 160, 204.

[141] A. A. Popova, D. Marcato, R. Peravali, I. Wehl, U. Schepers, P. A. Levkin, Adv. Funct. Mater. 2017, 28, 1703486.
[142] Surface tension values of some liquids were obtained from, http:// www.surface-tension.de/ (accessed: December 2017).

[143] Surface tension value of Krytox was obtained from, http://www2. dupont.com/Lubricants/ (accessed: December 2017).

[144] a) J. D. Michaels, J. E. Nowak, A. K. Mallik, K. Koczo, D. T. Wasan, E. T. Papoutsakis, Biotechnol. Bioeng. 1995, 47, 420; b) FBS is the abbreviation of Fetal Bovine Serum. 
Karlsruher Institut für Technologie

\section{Repository KITopen}

Dies ist ein Postprint/begutachtetes Manuskript.

Empfohlene Zitierung:

Feng, W.; Ueda, E.; Levkin, P. A. Droplet Microarrays: From Surface Patterning to High-Throughput Applications. 2018. Advanced materials, 30. DOI: $10.5445 / / R / 1000082431$

Zitierung der Originalveröffentlichung:

Feng, W.; Ueda, E.; Levkin, P. A.

Droplet Microarrays: From Surface Patterning to High-Throughput Applications. 2018. Advanced materials, 30 (20), 1706111.

DOI: $\underline{10.1002 / a d m a .201706111}$ 